\title{
Risk for Psychopathology in the Children of Depressed Mothers: A Developmental Model for Understanding Mechanisms of Transmission
}

\author{
Sherryl H. Goodman \\ Emory University
}

\author{
Ian H. Gotlib \\ Stanford University
}

\begin{abstract}
A large body of literature documents the adverse effects of maternal depression on the functioning and development of offspring. Although investigators have identified factors associated with risk for abnormal development and psychopathology in the children, little attention has been paid to the mechanisms explaining the transmission of risk from the mothers to the children. Moreover, no existing model both guides understanding of the various processes' interrelatedness and considers the role of development in explicating the manifestation of risk in the children. This article proposes a developmentally sensitive, integrative model for understanding children's risk in relation to maternal depression. Four mechanisms through which risk might be transmitted are evaluated: (a) heritability of depression; (b) innate dysfunctional neuroregulatory mechanisms; (c) exposure to negative maternal cognitions, behaviors, and affect; and (d) the stressful context of the children's lives. Three factors that might moderate this risk are considered: (a) the father's health and involvement with the child, (b) the course and timing of the mother's depression, and (c) characteristics of the child. Relevant issues are discussed, and promising directions for future research are suggested.
\end{abstract}

Much has been written about the adverse effects of mothers' depression on their children. Most of that work has focused on documenting the negative outcomes in functioning and diagnostic status of children whose mothers are clinically or subclinically depressed. Given the consistency of the results of studies in this area, there is no question that children are adversely affected by their mothers' depression. ${ }^{1}$ Indeed, negative effects of maternal depression have been documented in children ranging in age from infancy through adolescence. For example, compared with offspring of nondepressed controls, infants of depressed mothers have been found to be more fussy, to obtain lower scores on measures of mental and motor development, and to have more difficult temperaments and less secure attachments to their mothers. Toddlers of depressed mothers have been found to react more negatively to stress and to be delayed in their acquisition of effective self-regulation strategies. Finally, relative to control children, school-aged children and adolescents whose mothers are depressed have been found to have more school problems, to be less socially competent, and to have lower levels of self-esteem and higher levels of behavior problems (for recent reviews of these literatures see Cummings \& Davies, 1994; Gotlib \& Goodman, 1999; and Gotlib \& Lee, 1996).

Recently, researchers have attempted to move beyond an examination of the relatively simple question of whether children of

Sherryl H. Goodman, Department of Psychology, Emory University; Ian H. Gotlib, Department of Psychology, Stanford University.

Preparation of this article was supported by Grant MH 59259 from the National Institute of Mental Health.

We thank Donna Gelfand and Mahzarin Banaji for their helpful comments on a draft of this article.

Correspondence concerning this article should be addressed to Sherryl H. Goodman, Department of Psychology, 532 Kilgo Circle, Emory University, Atlanta, Georgia 30322. Electronic mail may be sent to psysg@emory.edu. depressed mothers are at risk for abnormal development and have begun to identify factors that are associated with this risk. Despite this shift in focus, however, we currently have little understanding of why and how these children are at risk. That is, relative to our knowledge of the range of adverse outcomes for children of depressed mothers, we know little about the mechanisms that underlie the risk for these outcomes. What are the likely mechanisms through which risk for adverse outcomes in children of depressed mothers might be transmitted? How might multiple mechanisms interact when they co-occur? How are specific mechanisms related to particular outcomes in the children? In what ways might mechanisms feed back to each other in bidirectional or dynamic processes? What are the possible or likely pathways to disorder in children of depressed mothers? And what is the role of developmental factors in the association between depression in mothers and the emergence of psychopathology in the children?

The purpose of this article is to propose and begin to evaluate an integrative, developmentally sensitive model for the understanding of children's risk as a function of maternal depression. The major goals in presenting this model are to (a) address mechanisms underlying the elevated risk for dysfunction that characterizes children of depressed mothers, (b) cut across the lines that have traditionally separated studies of genetic-biological factors and investigations of cognitive-interpersonal factors in depression, and

\footnotetext{
${ }^{1}$ Although fathers may also pose a risk for their children, the focus of this article is on depression in mothers. Women experience clinically significant depression at about twice the rate as men (Blehar \& Oren, 1995). In part because of this gender difference, women have been the focus of the vast majority of the scientific studies in the area of depressive disorders. Moreover, as we contend later in this article, because of their role women are implicated specifically in several of the risk mechanisms proposed in this article.
} 
(c) be consistent with principles of developmental psychopathology. Although the functioning of children of depressed mothers has been the subject of a number of reviews (e.g., Cummings \& Davies, 1994; Field, 1992; Gelfand \& Teti, 1990; Goodman, 1992; Gotlib \& Goodman, 1999; Gotlib \& Lee, 1990, 1996; Hammen, 1991), the present article is unique in proposing and evaluating an integrative, developmentally sensitive theoretical model of the mechanisms of risk. Unlike those earlier reviews, the present article is not a comprehensive review of the descriptive literature examining the functioning of offspring of depressed mothers. Rather, the primary goals of this article are to propose and evaluate an integrative model of risk to children of depressed mothers and to set an agenda to guide future process research in this area.

We begin by introducing three principles that guided our development of the conceptual model: the role of a model, the need to consider reciprocal and transactional relationships, and the need to take a developmental perspective. Then we present the model, briefly discussing its components and outlining possible patterns of dynamic interplay among the components. Next, we discuss four mechanisms through which we propose that risk to the children of depressed mothers might be conferred: (a) heritability of depression; (b) innate dysfunctional neuroregulatory mechanisms; (c) exposure to negative maternal cognitions, behaviors, and affect; and (d) the stressful context of the children's lives. For each of the mechanisms, we review the results of relevant studies and summarize the status of current knowledge. We then present a similar review of three potential moderators of the association between maternal depression and negative outcomes in the children: the father's health and involvement with the child, the course and timing of the mother's depression, and characteristics of the child, such as gender and temperament.

In the final section of the article, we raise several issues, and, in the context of those issues, we identify both theoretical and empirical gaps in our knowledge and provide what we believe are promising directions for future research in this field. First, we consider the strengths and limitations of the proposed mechanisms, focusing on the extent to which each mechanism has been supported by the empirical literature. We also examine the extent to which each mechanism addresses and accounts for reciprocal and transactional relationships between parent and child and among risk factors, and we examine whether it suggests developmental pathways to disorder in the children of depressed mothers. Second, we consider the level of theory that is most needed, arguing strongly for the advantages of an integrative model such as the one proposed in this article. Third, we examine the specificity of the model and the findings to maternal depression and to depression as the outcome of risk in the children. In this context we discuss the potential role of specific correlates of maternal depression and the difficulties engendered when investigators do not consider these correlates in their studies. Fourth, we explore the notions of sensitive periods and children's recovery from adversity.

\section{Principles Guiding the Development of the Conceptual Model}

\section{The Role of a Model}

Essentially, a model of risk in this area must provide guides to identifying variables that mediate or moderate the association between parental depression and negative outcome in the children (Baron \& Kenny, 1986). Mediation refers to mechanisms through which maternal depression may be associated with adverse child outcomes. Thus, factors that mediate may be any of the ways in which children or families with a depressed mother (or the subset of such children or families in which there are negative child outcomes) differ from children or families without a depressed mother (e.g., abnormal neuroregulatory mechanisms in the child, high levels of family stress, parents' marital conflict, etc.). In contrast, moderators refer to variables for which the effects of maternal depression on child functioning are different at different levels of that variable. Moderators, even those as simple as children's gender and age, might improve the predictive efficacy and add important explanatory power concerning when, and under what circumstances, maternal depression will be more strongly associated with negative outcomes in the children. In general, therefore, we must have a better understanding of both exacerbating and protective factors that contribute to the variability in the outcomes of children of depressed mothers.

\section{Reciprocal and Transactional Relationships}

Investigators increasingly have recognized the importance of both reciprocal and transactional relationships within families (e.g., Bell \& Harper, 1977; Sameroff, 1990). The child's characteristics may strongly influence his or her own developmental course as a function of the complex interplay between the parents and child over time (see, for instance, Lytton, 1990, on the contributions to antisocial behavior). For example, both gender and temperament are likely to play significant roles in the development of patterns of family interaction and in the emergence of psychopathology. Moreover, although we do not yet fully understand the natural course of disorders in childhood, it is likely that the emergence of risk factors at various points in the child's trajectory influence and change that trajectory, just as the current status of a child or family system may influence the emergence of a risk factor (cf. Gotlib \& Wheaton, 1997). Finally, it is also important to consider reciprocal and transactional relations among the factors that both mediate and moderate the association between maternal depression and child outcome and how they may influence the developmental trajectory toward disorder. We discuss this position more fully later in this article.

\section{A Developmental Perspective}

In general, a developmental perspective has been lacking in studies of children of depressed mothers. Knowledge of underlying developmental processes is critical to the study of risk for the development of psychopathology in children, as well as to the understanding of failures in the development of competence (Cicchetti \& Schneider-Rosen, 1986). Moreover, a solid understanding of developmental processes is also crucial in designing preventive interventions for children at risk for psychopathology (Goodman, 1984). To date, researchers have tended to study children of depressed mothers either in one developmental period or in such a broad age range that two or more distinct developmental stages are included (and confounded). Both these strategies fail to address developmental issues. Conclusions drawn from studies of children in one developmental stage cannot be presumed to generalize to 
another period in children's lives. Moreover, studies that group together children whose ages vary widely likely mask important developmental issues.

From a developmental perspective, it is also essential to consider the timing of the mother's depressive episode, especially of the first depressive episode during the child's lifetime, with respect to the age of the child. A developmental theory of risk must be sensitive to the normative maturational tasks that the child is attempting to master at the time of exposure to the mother's depression. In general, the older the child at the age of first exposure, the more likely it is that behavioral systems will have matured and, thus, that the child will be less vulnerable to adverse influences. It is also more likely that the child will have developed competencies that prepare him or her for successful coping (Compas, 1987; Sroufe \& Rutter, 1984).

A related issue involves the fact that, unlike other stressors to which children may be exposed, depression in adults is typically not a single, time-limited event. In fact, as many as $25 \%$ of major depressions may be chronic (Depue \& Monroe, 1986). Moreover, depression is also a recurrent disorder: Over $80 \%$ of depressed patients have more than one depressive episode (Belsher \& Costello, 1988). More than $50 \%$ relapse within 2 years of recovery (e.g., Keller \& Shapiro, 1981; Mueller et al., 1996); indeed, individuals with three or more previous episodes of depression may have a relapse rate as high as $40 \%$ within only 12 to 15 weeks after recovery (Keller, Shapiro, Lavori, \& Wolfe, 1982; Keller et al., 1992). Clearly, therefore, few children are exposed to only one episode of maternal depression. Unfortunately, researchers rarely assess and report either the child's age at first exposure or the number of episodes to which the child has been exposed (see Goodman, Brogan, Lynch, \& Fielding, 1993, and Hammen, Burge, \& Adrian, 1991, for exceptions). Because of this limitation, we are not able to draw on empirical data to evaluate this important developmental consideration. We do, however, provide some suggestions for research that would address these concerns.

Finally, a hallmark of the developmental psychopathology perspective is an examination of the pathways to disorder, including the causes and consequences of the emergence of risk factors in the children. The adverse outcomes that have been identified in children of depressed mothers, such as depression and other emotional disorders and adjustment difficulties, are known to unfold over time. Characteristics or tendencies of the children's behavior, affect, or psychobiological functioning may be risk factors or early signs of a disorder that has not yet emerged. These same characteristics and tendencies, therefore, may contribute to the increased risk for the disorder. In addition, some children will develop signs of maladjustment that may or may not progress to disorder. We evaluate our proposed model for its potential to address these issues of alternative pathways to disorder.

\section{An Integrative Model of the Transmission of Risk to Children of Depressed Mothers}

A model that will significantly advance the study of children of depressed mothers is one that integrates biological and environmental considerations within a transactional perspective, that acknowledges the crucial role played by factors that may mediate and moderate the effects of maternal depression on children, and that is sensitive to developmental issues. Such an integrative model is presented in Figure 1. Essentially, as can be seen from Figure 1, the model posits that there are four potential mechanisms through which maternal depression adversely affects child functioning. In addition, we propose three factors that may moderate the association between maternal depression and child dysfunction.

The first point in this model is a depressed mother. ${ }^{2}$ In turn, having a depressed mother increases the likelihood of the presence and operation of one or more of four proposed mechanisms for the transmission of risk to the child: (a) heritability of depression; (b) innate dysfunctional neuroregulatory mechanisms; (c) negative maternal cognitions, behaviors, and affect; and (d) the stressful context of the children's lives. Although all of these represent potential mechanisms for the transmission of risk for psychopathology, any particular depressed mother-child dyad may be characterized by one, more than one, or, arguably least frequently, none of these mechanisms.

The model assumes further that a number of the proposed mechanisms will interact with one another and, consequently, is intended as a guide for exploring such interactions as they may affect the transmission of risk. In particular, genetic factors probably interact with all of the other mechanisms and moderators. Similarly, biological and psychosocial mechanisms also likely interact. Later in this article we describe the potential benefits of exploring gene-environment interactions, correlations, and covariation, and we describe stress-diathesis models.

As indicated in Figure 1, the occurrence of one or more of the proposed mechanisms for the transmission of risk is associated with the emergence of vulnerabilities in the offspring in any of several domains of functioning, including psychobiological (the central nervous system, especially the hypothalamic-pituitaryadrenocortical [HPA] axis), cognitive (e.g., dysfunctional cognitions, low self-esteem, helplessness or hopelessness beliefs, biased attention or memory functioning), affective (e.g., low stress resilience, difficulties in emotional regulation), and behavioral or interpersonal (e.g., inadequate social and social-cognitive skills, dysfunctional impulse control, problems in concentration, low mastery motivation).

Although we have presented these vulnerabilities as discrete categories, it is important to recognize that they, like the risk mechanisms, will almost certainly interact and affect one another. For example, children who are characterized by dysregulation of the HPA axis may be predisposed both to act in a lethargic manner and to exhibit hyper-responsiveness to the challenges of novel environments (Coplan et al., 1996). These tendencies would be expected to lead to a low rate of rewarding experiences, another vulnerability to depression. Furthermore, as part of a dynamic family system in which these behaviors in the child are exhibited to the mother, they may lead to an increase in maternal stress, lower maternal perceived parenting efficacy, and poorer quality of mother-child interactions. In essence, therefore, this proposed model for the transmission of risk to children of depressed mothers

\footnotetext{
${ }^{2}$ It should be pointed out here that a number of factors, both alone and in interaction, affect the probability of depression in a mother (e.g., genetic factors, cognitive vulnerability, stressful life events, etc.). It is beyond the scope of this article to review these disparate literatures, but specific studies and findings are presented and integrated in this article when they are relevant.
} 
$\begin{array}{lll}\text { Risk } & \text { Mechanisms } & \text { Oulnerabilities }\end{array}$

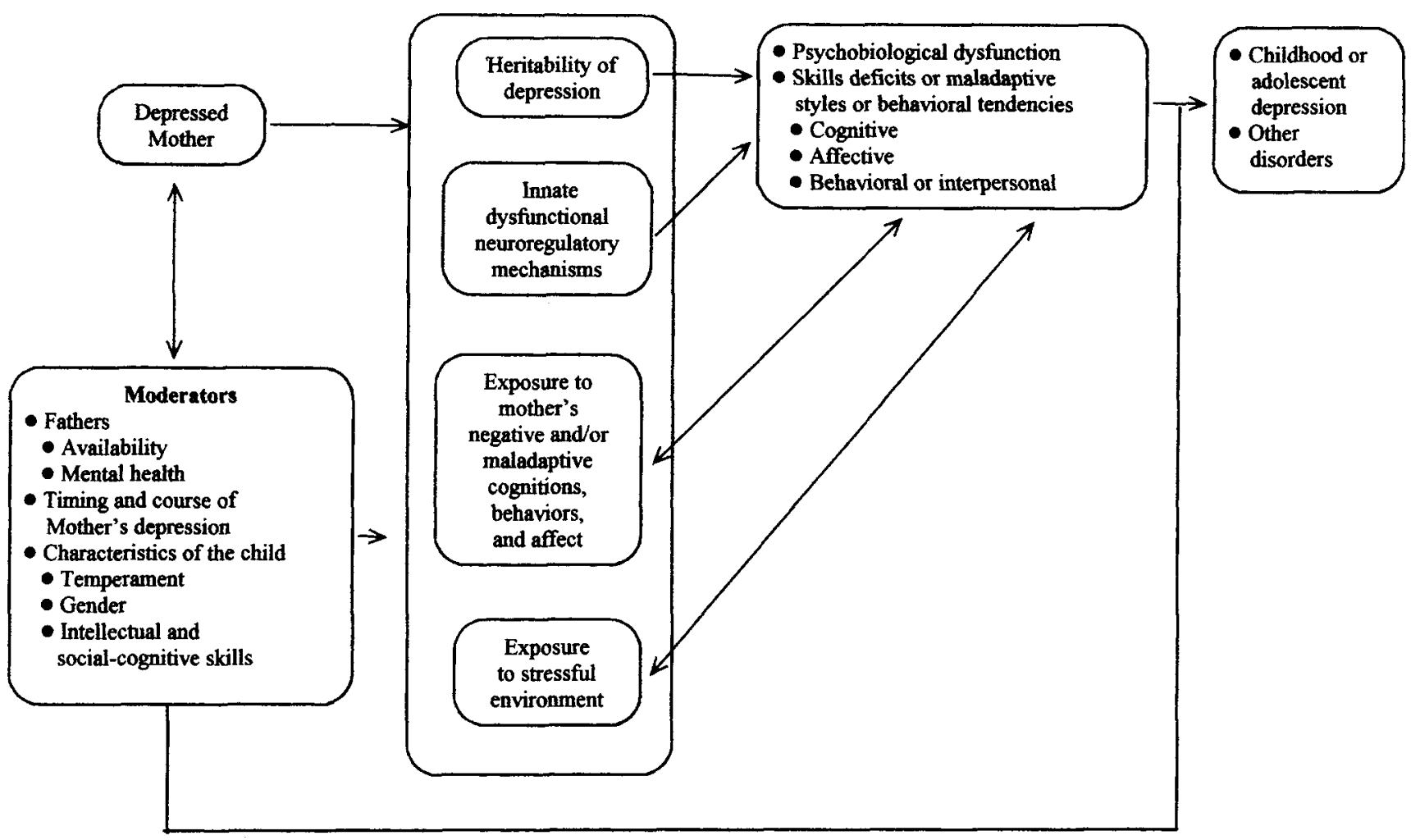

Figure 1. An integrative model for the transmission of risk to children of depressed mothers.

reflects the reality of bio-behavioral organisms, in that biological aspects of functioning are inextricably linked with psychological aspects of functioning. That link has been absent from most of the research on children with depressed mothers.

Finally, the model proposes that these vulnerabilities interact with three potential moderators: the father's health and involvement with the child, the course and timing of the mother's depression, and characteristics of the child, such as gender and temperament. The interactions of these vulnerabilities and moderators increase the likelihood of the development of psychopathology in childhood or adolescence, or, at a minimum, deficits in social, emotional, or cognitive functioning. We turn now to an extended discussion of each of the four proposed mechanisms for the transmission of risk to children of depressed mothers.

\section{Mechanisms of Transmission of Risk}

What is it about having a depressed mother that places a child at increased risk for abnormal development? As we noted above, we propose four possible mechanisms for the transmission of risk to children of depressed mothers, as well as three variables that might moderate these associations. Two of the proposed mechanisms are primarily biological in nature: One focuses on genetic factors (the heritability either of depression per se or of vulnerabilities to depression), and the other implicates dysfunctions in innate neu- roregulation. The third mechanism focuses on disturbed interpersonal processes between depressed mothers and their children including children's exposure to and social learning of their mothers' maladaptive or negative cognitions, behavior, and affect. Finally, the fourth mechanism for the transmission of risk implicates the stressful context of the children's lives.

\section{Mechanism 1: Having a Depressed Mother Confers on the Child a Genetic Predisposition to Depression}

Mechanism 1 explains in simple terms that children born to mothers who are, or who have been, depressed inherit DNA that is different in important ways from that inherited by children of nondepressed mothers. The DNA is assumed to regulate the biological mechanisms of these children in ways that serve to increase or decrease their vulnerability to depression. Thus, children of depressed mothers may inherit directly a vulnerability to depression.

It is also possible that, in the same manner, children of depressed mothers inherit vulnerabilities to personality traits, cognitive or interpersonal style variables, or environmental characteristics or experiences, which themselves increase the risk for the development of depression. Examples of such variables include inhibited temperamental style, shyness, negative affectivity, low self-esteem, negatively biased perceptions of the environment, low 
sociability, and the likelihood of experiencing poor parenting quality, life stress, and parental marital conflict and divorce. These variables could increase the risk for depression in children by leading them to select or avoid particular types of environments, to attend or respond selectively to certain aspects of their environments, thereby resulting in biased perceptions of the interpersonal world, or to experience a disproportionate number of stressors. These characteristics, in turn, may place the child at increased risk for developing a depressive disorder. In this section of the article, we examine evidence for both direct and indirect heritability of vulnerability to depression.

Empirical support. There is a considerable body of literature demonstrating a consistent pattern of genetic transmission of depressive disorders in adults. Considering all of the data obtained in investigations using twin, adoption, and family study designs, the risk for an affective disorder in adult first-degree relatives of a patient with unipolar affective disorder is estimated at $20-25 \%$, compared with a general population risk of $7 \%$ (for reviews see Nurnberger, Goldin, \& Gershon, 1986; Tsuang \& Faraone, 1990).

In addition to this high heritability of adult depression, two specific findings are particularly relevant for the study of children with depressed mothers, one concerning the severity of the mother's depression and the other involving the timing of the mother's depression. The first finding concerns the issue of clinical versus subclinical levels of depression. The relevant finding from recent twin studies is that narrowly defined major (i.e., clinically significant) depression is associated with high heritability (i.e., $79 \%$ of the variance accounted for by additive genetic effects) and only a small role of a common family environment; in contrast, the more common, milder (i.e., subclinical) forms of depression in adults appear to be influenced predominantly by environmental factors (e.g., Kendler et al., 1995; Kendler, Neale, Kessler, Heath, \& Eaves, 1993; McGuffin \& Katz, 1993; McGuffin et al., 1993; Plomin, 1990). Thus, studies examining women who are clinically depressed may differ from investigations focusing on women who are characterized by elevated scores on depression rating scales in the extent to which pathology in the child is mediated genetically.

The second finding from the genetic investigations of adult depression that is relevant to the study of children of depressed mothers involves the timing of the mother's depression with respect to the age of the child. Weissman et al. (1984) found that adult depressives with onset before age 20 have a higher familial aggregation than do those with later onsets. Moreover, compared with women with lower familial aggregation, women with higher familial aggregation have been found to be more likely to experience postpartum depression in response to the normal challenges of pregnancy and childbirth (O'Hara, 1986) ${ }^{3}$ The implications of these findings for genetic risk to children are important but are rarely acknowledged: Offspring of mothers with early-onset depression, particularly during the postpartum period, may carry a higher heritability for depression than do children whose mothers' depressions occur later in their lives (cf. Weissman, Warner, Wickramaratne, \& Prusoff, 1988).

In sum, there is little question that depression in adults has a high degree of heritability. It is important, however, to examine more directly the heritability of depression occurring in childhood, particularly given the high rates of depression that have been documented in children of depressed mothers. Although studies of family history, or family aggregation, offer some support for the heritability of childhood-onset depression, they have an inherent limitation of not being able to disentangle influences of genetic factors and family environment (but see Todd, Neuman, Geller, Fox, \& Hickok, 1993, for an application of segregation analysis to address this limitation). Merikangas, Weissman, Prusoff, and John (1988) found that the presence of a depressed spouse or of firstdegree relatives with a psychiatric illness increased the risk of a psychiatric diagnosis in the children of depressed mothers. Similarly, Weissman et al. (1987) reported that children who become depressed manifest the disorder at an earlier age ( $M$ age of onset $=12.7$ years) if they have a depressed mother than if their mother is not depressed ( $M$ age of onset $=16.8$ years). Moreover, Weissman et al. (1988) found that early-onset depression in a mother (i.e., before age 20 ) was associated with a 14 -fold increase in the risk of onset of major depression before age 13 years in their children. Weissman et al. interpreted this finding as further evidence for greater genetic contribution to depression in the offspring of parents with early-onset major depression. It seems clear, therefore, that depression in parents and other first-degree relatives increases the risk for depression in children and adolescents.

Other family studies in which a depressed child, rather than a depressed adult or parent, is identified as the proband have reported elevated prevalence rates for affective disorders among first- and second-degree aduit relatives. This pattern has been obtained with relatives of depressed prepubertal children (aged 6-12 years; Kovacs, Devlin, Pollock, Richards, \& Mukerji, 1997; Puig-Antich et al., 1989; Todd, Geller, Neuman, Fox, \& Hickok, 1996; Todd et al., 1993), of depressed adolescents (mean age 15 years; Kutcher \& Marton, 1991; Williamson et al., 1995), and of a mixed-age group of 7- to 17-year-old depressed children (Mitchell, McCauley, Burke, Calderon, \& Schloredt, 1989). Moreover, the results of segregation analyses conducted by Todd et al. (1993) indicate not only that genetic transmission of risk is more important than environmental transmission but, further, that transmission appears to conform to an additive model of risk; that is, the degree of risk increases in a linear fashion with the number of affected relatives. Considered collectively, the results of these studies highlight the importance of genetic transmission of risk in child- and adolescent-onset depression.

Consistent with importance of early-onset depression described above, other investigators have found rates of depressive illness to be higher in relatives of depressed children than they are in relatives of both depressed adolescents (e.g., Williamson et al., 1995) and depressed adults (Kovacs et al., 1997). Interestingly, both Williamson et al. and Kovacs et al. found that first-degree relatives of depressed children or adolescents with comorbid behavior disorders (e.g., attention deficit disorder, conduct disorder, and substance use-abuse disorders) themselves had higher rates of alcoholism, substance abuse, and antisocial personality disorders. These findings are discussed later in this article with respect to the issues of the specificity of children's risk to maternal depression,

\footnotetext{
${ }^{3}$ Earlier age of onset of depression in women would increase the likelihood both that their children would be exposed early in their development and, given the high rates of recurrence of depression, that they would be exposed to multiple episodes. Thus, early exposure to maternal depression is likely confounded with higher genetic risk. We expand on this point later in the article.
} 
rather than its correlates (including comorbid disorders) and with respect to the need to explicate alternative models to explain different outcomes for children of depressed mothers.

Four recent twin studies provide more direct tests of this proposed genetic mechanism of transmission of risk. Those studies demonstrate that the extent of genetic influence varies considerably with the child's severity of depression, the age of onset of depression, and the child's gender. Importantly, however, all of those studies are limited by having examined the genetic contribution to risk for depressive symptoms rather than for diagnosed depression.

With respect to severity of the child's depression, Rende, Plomin, Reiss, and Hetherington (1993) conducted a twin and halfsibling study analysis of 9- to 18-year-olds using scores on the Children's Depression Inventory (CDI; Kovacs, 1992). Rende et al. found moderate support for heritability of depressive symptoms (the individual heritability estimate, $h^{2}$, was significant at $.34 \pm$ .14) and little support for shared environmental influence. Interestingly, however, when the same analyses were conducted for the subgroup of children who scored above a clinical cutoff on the CDI, the results were reversed: Genetic influence was no longer significant, but shared environmental influences were significant.

Harrington, Rutter, and Fombonne (1996) and Thapar and McGuffin (1996) found that in 8- to 10-year-old twins, depressive symptoms, measured by summing parents' and children's scores on a shortened Mood and Feelings Questionnaire (MFQ; Costello \& Angold, 1988), were more strongly associated with family discord and other qualities of shared environmental factors than they were with genetic factors. In contrast, in older (11- to 16year-old) twins, depressive symptoms were more strongly associated with genetic than with environmental factors. Consistent with this pattern of results, K. T. Murray and Sines (1996) found that for 4- to 6-year-old twins, variance in the mothers' scores on the Missouri Children's Behavior Checklist (MCBL) was explained by environmental factors only (predominantly nonshared environmental factors). In contrast, for older (7- to 12-year-old) twins, nearly half of the variance in mothers' MCBL scores was attributable to genetic factors, with nonshared environmental factors accounting for the remainder.

Finally, with respect to gender, K. T. Murray and Sines (1996) also found different loadings of genetic and environmental factors for boys and girls in explaining transmission of depressive symptoms. For girls, additive genetic factors accounted for about $40 \%$ of the variance in mothers' MCBL scores, and both shared and nonshared family environmental factors contributed significantly to the equation. In contrast, for boys only nonshared environmental factors accounted for significant proportions of the variance in the MCBL scores. Thus, there is no single estimate of the extent of genetic contribution to children's depressive symptoms, with the estimate varying by severity of symptoms and children's age and gender.

We now turn to the question of heritability of specific traits or environmental factors that increase vulnerability to depression. Behavior genetics analyses have demonstrated that several correlates of, if not risk factors for, depression in children are highly heritable (for a review, see Loehlin, 1992). These factors include temperament (H. H. Goldsmith, Buss, \& Lemery, 1997; Plomin et al., 1993), behavioral inhibition and shyness (Cherny, Fulker, Corley, Plomin, \& DeFries, 1994), low self-esteem (Loehlin \&
Nichols, 1976), neuroticism (Tellegen et al., 1988), sociability (Plomin et al., 1993), subjective well-being (Lykken \& Tellegen, 1996), and expression of negative emotion (Plomin et al., 1993). Although not yet examined in children, genetic factors have also been found to contribute to individual differences in perceived adequacy of social support and the availability of a close and confiding relationship but not in the quantity or frequency of social interactions (cf. Bergeman, Plomin, Pedersen, McClearn, \& Nesselroade, 1990; Kessler, Kendler, Heath, Neale, \& Eaves, 1992; Roberts \& Gotlib, 1997). Importantly, both Bergman et al. and Kessler et al. found support for partial genetic mediation of the well-established association between social support and risk for depression (cf. Cohen \& Wills, 1985).

A number of theorists have recently contended that many of the environmental variables that increase children's vulnerability to depression may themselves be heritable. For example, Plomin (1994) argued that genetic factors contribute to differences in variables such as poor parenting quality, life stress, and marital conflict, which have typically been conceptualized as "environmental" rather than as genetically mediated. Indeed, using quantitative genetic methods and analyses, researchers have now demonstrated that genetic factors contribute to both self-reported and observed parenting and family environment measures (Braungart, 1994; O’Connor, Hetherington, Reiss, \& Plomin, 1995; Plomin, Reiss, Hetherington, \& Howe, 1994). In these studies, adopted monozygotic twins were found to be more similar to each other than were adopted dizygotic twins with respect to several aspects of their family environments, even though both types of twins had been reared apart. In fact, almost $25 \%$ of the variance in family environment was found to be genetic in origin (O'Connor et al., 1995; Plomin et al., 1994). Similarly, Kendler, Neale, Heath, Kessler, and Eaves (1991), McGuffin and Katz (1993), and Plomin (1990) all recently reported evidence indicating that life events or stressors, which often have been associated with depression (cf. Brown \& Harris, 1978), have a significant genetic component. And McGue and Lykken (1992) found strong evidence for the influence of genetic factors in the risk for divorce. Thus, the likelihood that children will experience stressful environments also appears to be genetically mediated.

Summary. The strongest and clearest conclusion that can be drawn from the genetics research reviewed above is that there is a substantial genetic contribution to depression in adults. The genetic contribution in adults appears to be greater for depression that meets diagnostic criteria than for depression that is measured solely by scores on symptom checklists; the genetic contribution is also greater for early- than for late-onset depressions. Given that the major outcome of interest among children with depressed mothers is depression occurring during childhood or adolescence, however, we also examined evidence that genetic vulnerability mediates these early-onset depressions. The support for heritability of childhood- or adolescence-onset depression is less clear than that for adult-onset depression. The strongest support comes from familial aggregation studies, although they are characterized by a number of inherent limitations. Findings from the twin studies are inconclusive and, further, are limited to children's depressive symptoms rather than clinically significant depression.

At this point, therefore, we cannot make strong statements concerning the extent to which heritability mediates the association between maternal depression and child psychopathology. In 
addition, the strength of the genetic contribution appears to vary with a number of factors. For example, for less severe childhood depression, and for girls, heritability has been found to be a stronger factor than are environmental variables. In contrast, for more severe levels of depression in children and particularly in boys, environmental factors seem to have a stronger influence than does heritability. Finally, the genetic model also contributes to our understanding of the issue of specificity of outcome for the children of depressed mothers. That is, familial patterns of transmission from parent to child seem to include the common comorbid disorders of alcoholism, substance abuse, and conduct-antisocial personality disorders, suggesting that the risk to children of depressed mothers is nonspecific, with respect to both the risk factors for psychopathology in the children and the diverse outcomes that the children experience.

Finally, the studies that are relevant to the possibility of inherited vulnerabilities to depression contribute to our understanding of children of depressed mothers in several respects. First, they correct inaccurate but prevalent conceptualizations of environmental variables that result from not taking into consideration their substantial genetic influences. Second, these studies broaden the perspective taken by more traditional genetic positions by suggesting that children of depressed mothers might inherit not only a tendency to experience depression but also an elevated risk of acquiring personal characteristics that are associated with vulnerability to depression and an elevated risk of experiencing stressful life events, including exposure to poor parenting, marital conflict, and their parents' divorce. All of these personal tendencies and experiences could be triggers for later depressive episodes in individuals who are already sensitized or vulnerable to depression. Third, and perhaps most importantly, these studies provide an opportunity to reconsider our assumptions about the mechanisms by which such variables as parenting, life stress, and divorce might influence children of depressed mothers. At minimum, psychosocial models alone, such as parental role models or models focusing on poor parenting, are inadequate to explain the association between maternal depression and child dysfunction. Nevertheless, despite the strong evidence for heritability of many of the risk factors for depression, studies have not yet been conducted explicitly to test the role of heritability of these risk factors as mediators of the association between maternal depression and psychopathology in the children.

\section{Mechanism 2: Infants of Depressed Mothers Are Born With Dysfunctional Neuroregulatory Mechanisms That Interfere With Emotional Regulation Processes and, Consequently, Increase Vulnerability to Depression ${ }^{4}$}

Mechanism 2 proposes that children of depressed mothers are born with dysfunctional neuroregulatory mechanisms. Although these may be a function of either genetic factors or adverse prenatal experiences, in this section we place a greater emphasis on the latter possibility. That is, the dysfunctional neuroregulatory mechanisms are hypothesized to be a direct effect of abnormal fetal developments caused by the mothers' depression during pregnancy; these abnormal developments could be due to such factors as the fetus' exposure to the neuroendocrine alterations associated with the mother's depression, constricted blood flow to the fetus, and so on. Thus, this mechanism is restricted to infants born to mothers who experience a clinically significant episode of depression during the pregnancy or who suffered a previous episode from which their neuroendocrine dysfunction has not recovered. The proposed abnormal fetal developments may be manifested at birth as behavioral traits or tendencies, such as a tendency to react to certain events with a particular response style (Calkins, 1994; Kagan, Reznick, \& Snidman 1988). Examples might be behavioral inhibition or negative affectivity. These traits or tendencies, in turn, increase children's vulnerability to develop depression. An alternative, diathesis-stress position is that the potential dysfunction is actualized or manifested only in the context of a particular social environmental history (Kagan, 1994).

Empirical support. Support for Mechanism 2 comes primarily from two sets of studies. The first set of investigations includes studies examining the fetal environment provided by depressed women. Researchers in this area have focused on how particular aspects of the fetal environment may lead to abnormal fetal developments, which manifest themselves at birth as dysfunctional neuroregulatory mechanisms. In a second set of studies, researchers have examined newborns of depressed mothers for behavioral evidence of dysfunctional neuroregulatory mechanisms, with the assumption that these dysfunctions are related to adverse in utero environments.

Among the first set of studies, researchers have examined aspects of the fetal environment that may be specific to depressed women and that may be associated with abnormal fetal development. Among the factors that have been considered as possible mechanisms of abnormal fetal development among depressed women are (a) neuroendocrine abnormalities, (b) reduced blood flow to the fetus, (c) poor health behaviors, and (d) the use of antidepressant medication.

With respect to the neuroendocrine abnormalities, an important question to be addressed is whether the neuroendocrine correlates of the mother's depression are experienced by the fetus via utero blood flow. Because development begins in utero and the fetus' first transaction with the mother occurs at gestational days 13-14, when utero blood flow is established, the fetus might be affected by the neuroendocrine correlates of the mother's depression well before birth. Two studies examined the neurobiology of pregnant, depressed women and found plasma cortisol, beta-endorphin, and corticotrophin releasing hormone (CRH) levels to be higher among women who rated elevated levels of depressed mood at 28 to 38 weeks of gestation (Handley, Dunn, Waldron, \& Baker, 1980; Smith et al., 1990). Similarly, Field (1998) found higher urinary cortisol and norepinephrine in depressed pregnant women. Studies of stress during pregnancy, which is generally highly correlated with depression (e.g., Hammen, 1990; Lewinsohn, Hoberman, \& Rosenbaum, 1988), similarly conclude that stress during pregnancy is associated with increased levels of catecholamines, epinephrine, and norepinephrine; acute stress may be associated with cortisol release and immunosuppression (Emory, Hatch, Blackmore, \& Strock, 1993). Thus, as a group depressed women are

\footnotetext{
${ }^{4}$ Because these dysfunctions may reflect genetic risk, we could have included them in the previous section. However, the dysfunctions may also reflect in utero environmental hazards. Consequently, we are treating this as a separate mechanism.
} 
characterized by abnormal neuroendocrine functioning during pregnancy.

Few studies have examined specifically whether these hormones cross the placenta to the fetus. Glover, Teixeira, Gitau, and Fisk (1998) reported no significant correlation between fetal and maternal hormone levels at 20-36 weeks of pregnancy with the single exception of cortisol; maternal levels of cortisol accounted for $50 \%$ of the variance in the fetus' levels of cortisol. This finding suggests that maternal cortisol crosses the placenta. Our knowl edge of the psychobiology of depression justifies our concern for infants who, as fetuses, were exposed to corticotropin-releasing factor (CRF) hypersecretion. The consequences for infants of such exposure would be expected to be manifested in abnormal stress reactivity, abnormal behavioral and affective functioning, and abnormal EEG patterns. Each of these aspects of functioning is known to be disrupted in adult depression (Davidson \& Fox, 1988; Gotlib, Ranganath, \& Rosenfeld, 1998; see Gotlib \& Hammen, 1992, for a review of this research) and may represent markers of risk for depression in the infants of depressed mothers (Field, Pickens, Fox, Nawrocki, \& Gonzalez, 1995).

The second factor that has been considered as a possible mechanism of abnormal fetal development among depressed women is reduced blood flow to the fetus. Three studies are relevant to this issue. Glover (1997) conducted ultrasound tests on 100 nonsmoking, healthy women in their third trimester of pregnancy and found maternal trait anxiety to be associated with impaired uterine blood flow. Glover also found that low uterine blood flow was also associated with lower birth weight of the babies. Given the high comorbidity of depression and anxiety, it is likely that this pattern of findings would apply to depressed women as well. Interestingly, in support of this contention, Field (1998) reported that fetuses of women who were depressed during the pregnancy had lower estimated weight and engaged in less movement (Field, 1998) than did fetuses of control women. Finally, Emory, Walker, and Cruz (1983) found that stress during pregnancy (itself a correlate of depression) was associated with increased fetal heart rate, which in turn, in uncomplicated pregnancies and deliveries, is associated with lower attention orientation and arousal in the neonate. Considered together, these three studies provide indirect evidence that maternal depression during pregnancy may be associated with abnormal uterine blood flow and other difficulties in the fetuses and neonates.

The third factor through which fetuses of depressed women may be at elevated risk involves the inadequate health care and health risk behaviors that have been found to be associated with depression. Milberger, Biederman, Faraone, Chen, and Jones (1996), for example, found that depressed women are more likely than their nondepressed counterparts to obtain and receive inadequate prenatal care, to report unhealthy eating and sleeping patterns, and to engage in smoking. Each of these behaviors represents a risk factor for abnormal development of the fetus (cf. Milberger et al., 1996).

Finally, several recent studies have addressed the question of whether in utero exposure to antidepressant medications might contribute to the development of abnormal neurophysiology in the fetus. Both tricyclic antidepressants and fluoxetine, the two dominant medication treatments for major depression, do cross the placental barrier. Interestingly, however, recent evidence suggests that antidepressant medication taken during pregnancy has no discernible adverse effects on the fetus or infant. Both Pastuszak et al. (1993) and Chambers, Johnson, Dick, Felix, and Jones (1996) found that tricyclic or fluoxetine exposure in the first trimester of pregnancy was not related to increased risk of major malformations. And although Chambers et al. (1996) found increased risk for perinatal complications in infants of women who took fluoxetine in their third trimester, they did not correct for the greater severity of depression among women who needed continued medication throughout the pregnancy. More recently, Nulman et al. (1997) examined 16-month-olds to 7-year-old children whose mothers had received tricyclic antidepressants, fluoxetine, or no antidepressant medication during pregnancy. Nulman et al. assessed the offsprings' neurocognitive development (the Bayley Scales of Infant Development or the McCarthy Scales of Children's Abilities), temperament, behavior problems, and language skills and found no differences among the children of these three groups of mothers on any of these measures.

In the second set of studies that are relevant to this proposed mechanism for the transmission of risk to offspring of depressed mothers, investigators have examined the status of neonates of depressed mothers for behavioral evidence of dysfunctional neuroregulatory mechanisms. In one such set of studies, researchers found increased rates of premature births and lower birth weight among the neonates of depressed versus well mothers (e.g., Copper et al., 1996; Hedegaard, Henriksen, Secher, Hatch, \& Sabroe, 1996; Paarlberg, Vingerhoets, Passchier, Dekker, \& Van Geijn, 1995). Field and her colleagues also hypothesized a prenatal origin to the poor functioning of infants with depressed mothers (Field, 1992). They examined a group of mothers who had been identified as depressed during a prenatal examination and were later diagnosed with postpartum depression. Within a few days after birth, the neonates demonstrated poorer performance on the Brazelton Neonatal Behavior Assessment Scale orientation and depression clusters, including minimal responding to inanimate and social stimuli (suggesting higher sensory thresholds), decreased motor tone and lower activity levels, and less robustness and endurance (Abrams, Field, Scafidi, \& Prodromidis, 1995; Field, Sandberg, Garcia, Vega-Lahr, Goldstein, \& Guy, 1985). Finally, Zuckerman, Bauchner, Parker, and Cabral (1990) studied a large group of neonates at 8 to $72 \mathrm{hr}$ after delivery and found a strong association between mothers' depression symptom scores obtained during pregnancy and excessive crying and inconsolability, as reported by pediatricians who were blind to the mothers' depression scores.

These findings on the status of neonates are consistent with the idea that infants of depressed mothers are born with dysfunctional neuroregulatory mechanisms. However, they are only behavioral manifestations and, as such, can only be suggested to reflect neuroregulatory dysfunction. The young age at which the neonates were studied makes it less likely that the measures reflect the infant's early reaction to the depressed mother.

Some animal studies also have data relevant to the question of innate dysfunctional neuroregulatory mechanisms. In studies of rhesus monkeys, mild maternal stress during pregnancy (exposure to unpredictable noise during mid-to-late gestation) was found to be associated with offspring lower birth weight, poorer neuromotor maturation, delayed cognitive development, and less exploration of novel stimuli in infancy (Schneider, 1992). As juveniles, those monkeys whose mothers had been stressed during pregnancy demonstrated abnormal social behavior and greater HPA activity (elevated cortisol) at baseline and, in particular, in response to stress 
(Clarke \& Schneider, 1993; Clarke, Wittwer, Abbott, \& Schneider, 1994). Similarly, rats that had been stressed by noise and light during pregnancy had offspring with lower birth weight, less vocalization during isolation in a novel environment, less exploration of novel environments, and suppressed immune function (Kay, Tarcic, Poltyrev, \& Weinstock, 1998; Poltyrev, Keshet, Kay, \& Weinstock, 1996; Williams, Hennessy, \& Davis, 1998). Although not directly tested, the mechanism implicated in this set of findings is an effect of maternal stress hormones on the developing fetal neuroendocrine system.

Summary. Researchers are beginning to find that depressed women have abnormal neuroendocrine functioning during pregnancy, that the fetus is exposed to an increase in cortisol level and to less blood flow; perhaps as a consequence, the fetuses of depressed women have also been found to be characterized by relatively slow growth and less movement. Much of this research is new and needs to be replicated. Other researchers have found abnormalities in neonates born to women who had been depressed during pregnancy. Although each of these early disturbances has been hypothesized to contribute to the subsequent emergence of psychopathology, none of these studies tested the role of these early behavioral anomalies as mediators of the association between maternal depression and depression in their children. For example, premature birth and low birth weight have been identified as increasing risk for mental retardation and for behavioral, emotional, and learning problems (Institute of Medicine, 1985; McGauhey, Starfield, Alexander, \& Ensminger, 1991). These studies are particularly important because they have assessed the infants' functioning before the infants have been exposed behaviorally to the depressed mother and therefore implicate abnormal fetal environments in the infants' abnormal functioning. Nonetheless, studies have not yet been conducted that would establish the roles of these variables as mediators of the association between maternal depression and psychopathology in the children.

\section{Mechanism 3: Depressed Mothers Expose Their Children to Negative or Maladaptive Cognitions, Behaviors, and Affect, Which Places the Children at Elevated Risk for Developing Depression}

Mechanism 3 entails a number of related components. First, depression in the parent is postulated to be associated with negative cognitions, behaviors, and affect. Second, because of these depressive cognitions, behaviors, and affect, the depressed parent is hypothesized to be an inadequate social partner for the child and to be unable to meet the child's social and emotional needs. The third component of this mechanism maintains that this inadequate parenting would negatively affect the child's development of social and cognitive skills and styles. Fourth, we postulate that through social learning or modeling, children acquire cognitions, behaviors, and affect that resemble those exhibited by their depressed mothers. The fifth and final component of this mechanism maintains that the children's acquired depressotypic cognitions, behaviors, and affect and their deficient skills and styles place them at elevated risk for developing depression.

Empirical support. The first component of Mechanism 3 postulates that depression in the parent is associated with negative cognitions, overt behaviors, and affect. Depressed persons have consistently been found to be characterized by more negative cognitive functioning than have their nondepressed counterparts. More specifically, depressed adults have been found to demonstrate negatively biased self-perceptions and cognitions, including more internal, stable, and global attributions for negative events; increased attention to, and memory for, negative stimuli; and high levels of self-punishment and low levels of self-reinforcement and self-efficacy (for reviews of this literature see Gotlib, Gilboa, \& Sommerfeld, in press; Gotlib \& Neubauer, in press). Importantly, depressed mothers' negative cognitions have been found to extend to their parenting. They are more likely to endorse negative views of themselves as parents (Gelfand \& Teti, 1990; Goodman, Sewell, Cooley, \& Leavitt, 1993), to view themselves as having less personal control over their children's development, and to see themselves as less likely to be able to positively influence their children (Kochanska, Radke-Yarrow, Kuczynski, \& Friedman, 1987).

There is also ample evidence that depressed mothers expose their children to depressive behaviors and affect. Researchers have found, for example, that compared with nondepressed persons, depressed individuals are more self-focused (Ingram, 1990; Pyszczynski \& Greenberg, 1987), engage in more negative conversational content (Gotlib \& Robinson, 1982; Kowalik \& Gotlib, 1987), and demonstrate more negative behaviors in interactions with others (Gotlib, 1982; Jacobson \& Anderson, 1982). Depressed persons also elicit feelings of depression, anxiety, and hostility in others with whom they interact (Gotlib \& Meltzer, 1987). Perhaps not surprisingly, therefore, individuals have been found to withdraw from interaction with depressed persons (cf. Gurtman, 1986; see Gotlib \& Whiffen, 1991, for a more detailed review of this literature).

Similar observations have been made with respect to more intimate interactions. For example, in interactions with their spouses, which, presumably, the children have opportunities to observe, depressed women have been found to engage in selfderogation, complaining, and dysfunctional problem-solving behavior and to exhibit elevated levels of hostility, anger, and conflict (e.g., Biglan et al., 1985; Gotlib \& Whiffen, 1989; Hinchliffe, Hooper, \& Roberts, 1978). In extensive home observations, Hops et al. (1987) found that depressed mothers' sadness was associated with less aggressive affect of other family members; conversely, family members' aggressive affect was observed to suppress the mothers' dysphoric affect.

Finally, several researchers have examined more explicitly the behaviors of depressed parents with their children (see Gotlib \& Goodman, 1999, for a review of this literature). Compared with nondepressed psychiatric and nonpsychiatric controls, depressed mothers have been observed in direct interactions with their children to display more sad and irritable affect (Cohn, Campbell, Matias, \& Hopkins, 1990; Hops et al., 1987; Radke-Yarrow \& Nottelmann, 1989); to be less positive, and more punitive, negative, and retaliatory with their children; to engage in more angry, intrusive, hostile, and conflictual behavior (Field, Healy, Goldstein, \& Guthertz, 1990; Goodman, Adamson, Riniti, \& Cole, 1994; Hammen, 1991); and either to be ineffective in resolving conflicts or to alternate between harsh, punitive discipline and lax undercontrol (Dumas, Gibson, \& Albin, 1989; Kochanska, Kuczynski, Radke-Yarrow, \& Welsh, 1987).

It is clear, therefore, that depressed persons in general, and depressed parents in particular, exhibit negative cognitions, behav- 
iors, and affect. The second component of Mechanism 3 contends that these cognitions and behaviors make it more likely that the depressed parent will be an inadequate social partner for the child and will be unable to meet the child's social and emotional needs. Given that children's parenting needs vary over the course of development, the actual proposed pathways for this component differ as a function of the age of the child at the time of the maternal depression(s). For infants, two key aspects of parenting are fostering an attachment relationship and facilitating the development of emotional self-regulation. Importantly, insensitive or unresponsive parenting has been found to be among the strongest predictors both of insecure attachment (e.g., Egeland \& Farber, 1984) and of infants' difficulty in establishing effective selfregulation skills (Tronick \& Gianino, 1986) and, further, may be related to problems in infants' development of neuroregulatory mechanisms (e.g., Dawson, Hessl, \& Frey, 1994; Field, 1992). At a more behavioral level, relative to their nondepressed counterparts, depressed mothers have been observed to provide lower amounts of and lower quality stimulation for their infants (Livingood, Daen, \& Smith, 1983); to be slower in responding, and less contingently responsive, to their infants (Bettes, 1988; Field, 1984; Field et al., 1990, 1985); and to use less reciprocal vocalization and affectionate contact with their infants (Fleming, Ruble, Flett, \& Shaul, 1988).

For toddlers and preschool-aged children, parents must provide the external support necessary for their children to develop an accurate understanding of social and emotional situations (Cicchetti \& Schneider-Rosen, 1986). The nature of this support includes providing their child with emotional language acquisition and socialization (Gottman, Katz, \& Hooven, 1996); guiding the behaviors of their toddlers in social referencing situations (cf. Campos \& Steinberg, 1981; Walden \& Ogan, 1988); facilitating their children's relationships with peers and other adults, as well as their involvement in extracurricular activities; and providing the young child with adequate "scaffolding," that is, providing external, verbal support that facilitates a child's movement from one developmental level of cognitive and social functioning to the next (D. F. Goldsmith \& Rogoff, 1995; Vygotsky, 1987). Toddlers or preschool-aged children whose parents did not provide for these needs would be predicted to have difficulties in the emergence of effective autonomous functioning, in the management of emotionally arousing situations, and in their ability to organize and coordinate environmental resources (Cicchetti \& Schneider-Rosen, 1986).

Investigators who have examined the interactions of depressed mothers with their toddlers and preschool-aged children have found that, compared with nondepressed controls, depressed mothers spend less time mutually engaged with their children in a shared activity (D. F. Goldsmith \& Rogoff, 1997). They also initiate and terminate their children's attention to objects more frequently, rather than encouraging sustained attention (Breznitz \& Friedman, 1988). When their children resist their attempts at control, depressed mothers avoid confrontation, either immediately dropping their original demands or persisting at control but failing to achieve a mutually negotiated compromise (Kochanska, Kuczynski, et al., 1987). Finally, depressed mothers and their toddlers and preschool-aged children have been found to engage in patterns of coercive mutual interpersonal influence, including what are described as retaliation and revenge (Kochanska, Kuczynski, \& Maguire, 1989).
For school-aged children and adolescents, the stage-salient needs shift to parents' provision of general social support or stress buffering (i.e., helping their children to cope with other stressors; cf. Lee \& Gotlib, 1991b), helping their children to maintain their focus on the cognitive-intellectual and social environment, and monitoring their children's behavior and providing consistent discipline (Hops et al., 1987; Hops, Sherman, \& Biglan, 1990; Patterson, 1982). Children whose parents fail to provide for these needs would be expected to experience school failures and behavioral and emotional problems. Interestingly, Hops et al. (1987) found depressed mothers to suppress their dysphoric affect in response to their children's aggressive affect, thereby reinforcing the children's misbehavior. Moreover, a number of investigators have found that depressed mothers, compared with their nondepressed counterparts, have more negative appraisals of, and lower tolerance for, their children's behaviors. Both of these variables, in turn, have been found to be associated with more punitive parenting and might further be expected to be associated with higher thresholds for rewarding behavior (e.g., Forehand, Lautenschlager, Faust, \& Graziano, 1986; Schaughency \& Lahey, 1985). Finally, depressed mothers have been observed to express more criticism of their children, both in direct interactions with their children (Hammen, Adrian, \& Hiroto, 1988; Webster-Stratton \& Hammond, 1988) and in interviews about their children (Goodman et al., 1994).

We should note here that, consistent with a cognitive perspective on depression, several researchers have contended that depressed mothers' perceptions of their children's behaviors are negatively distorted (e.g., Friedlander, Weiss, \& Taylor, 1986; Radke-Yarrow, Belmont, Nottelmann, \& Bottomly, 1990; Rickard, Forehand, Wells, Griest, \& McMahon, 1981). In contrast, other researchers argue that depressed mothers are accurate reporters of their children's behavior (Conrad \& Hammen, 1989; Richters \& Pelligrini, 1989). It is important to note that these studies may not reflect "accuracy" on the part of the mothers but, instead, may be inadvertently capitalizing on a "match" of children's more negative behaviors and depressed mothers' more negative response or reporting styles (cf. Coyne \& Gotlib, 1983). As Richters (1992) noted, studies are required examining whether depressed mothers report more child behavior problems than are reflected by independent, validated ratings of the same behaviors in the same setting. More recently, using a large sample and sophisticated methodology, Boyle and Pickles (1997) found that both maternal depression and the associated family dysfunction or stress may contribute to the mothers' negatively biased reports, especially concerning their younger (5- to 7-year-olds), as opposed to older (8- to 12-year-olds) children.

The results of studies of each developmental stage indicate, therefore, that depressed parents are characterized by negative perceptions of their children and by difficulties interacting with their children and meeting the children's social and emotional needs. The third component of Mechanism 3 maintains that this problematic parenting would negatively affect the children's development of social and cognitive skills and styles. There are two aspects of this component that are important. The first is whether children of depressed mothers are in fact characterized by deficits or delays in affective, behavioral, or cognitive skills or styles; the second is whether these delays or deficits are related to the mothers' inadequate parenting. 
What is the evidence that children of depressed mothers have deficits or delays in affective, behavioral, or cognitive skilis or styles? Several investigators have reported findings consistent with this component of the proposed mechanism. For example, researchers examining the attachment status and styles of infants of depressed mothers have found that these infants are characterized by insecure attachment (e.g., Radke-Yarrow, Cummings, Kuczynski, \& Chapman, 1985; Teti, Gelfand, Messinger, \& Isabella, 1995). More specifically, Teti et al. (1995) found greater levels of insecure attachment, and specifically the Anxious Depressed (Type AD) attachment classification, among preschoolers of depressed mothers (Type AD is identified by several depressive-like features, including sad or flat affect, lethargy, or panic on separation, and an overall style of disorganization). Further, disorganized attachment behavior in the infants has been found to be related to the severity and chronicity of the mother's depression (Campbell \& Cohn, 1997; Teti et al., 1995).

Several investigators have documented the presence of other types of deficits or delays in children of depressed mothers. Field and colleagues (Field, 1994; Field, Pickens, et al., 1995), for example, found that, compared with infants of nondepressed mothers, infants of depressed mothers showed delayed development of autonomic regulation at 6 months, as evidenced by lower vagal tone. Similarly, Dawson and her colleagues (e.g., Dawson, Grofer Klinger, Panagiotides, Hill, \& Spieker, 1992; Dawson et al., 1994) found that infants of depressed mothers exhibit reduced left frontal brain activity compared with infants of nondepressed mothers, likely reflecting lower approach-related behavior. Compared with toddlers of nondepressed mothers, children of depressed mothers have been found to exhibit high levels of anxiety during a mildly stressful situation (Radke-Yarrow \& Sherman, 1985) and less sustained attention to objects during spontaneous play with their mothers (Breznitz \& Friedman, 1988). Finally, Goodman, Brogan, et al. (1993) found that 5- to 10-year-old children of mothers with a history of unipolar depression were rated by their teachers as less popular with peers than were children of well mothers. Thus children of depressed mothers have been found to be characterized by deficits or delays in affective, interpersonal, cognitive, and bio-behavioral skills and styles.

The second aspect essential to the consideration that problematic parenting would negatively affect children's social and cognitive development is whether the biases, delays, or deficits that have been identified in children of depressed mothers are related to inadequate parenting. Most of the data that are relevant to this question come from observations of mother-child interaction in which the synchronies, contingencies, or patterns of behaviors between the mothers and children are interpreted as reflecting the consequences of inadequate parenting. For example, infants interacting with their depressed mothers, or with mothers who were simulating depression and who were relatively unresponsive to the infants, were found to exhibit predominantly negative affect in their facial expression and gestures; the infants were observed initially to persist in attempts to obtain the external regulation they needed from their mothers, but they eventually began to engage in self-directed regulatory behaviors (Gianino \& Tronick, 1985; Tronick \& Gianino, 1986). Similarly, infants of depressed mothers who were intrusive looked less at their mothers in interactions; with depressed mothers who were withdrawn, infants protested and appeared distressed (Cohn, Matias, Tronick, Connell, \& Lyons-Ruth, 1986; Tronick, 1989).

Conceptually similar findings have been obtained with older children of depressed mothers. For example, reminiscent of Patterson's (1982) coercive family process model, ${ }^{5}$ Kochanska et al. (1989) found that in a sample of mothers with a history of depression, negative maternal mood and the child's resistance to the mother increased the likelihood of the mothers' aversive responses to their children. Other investigators have observed children as young as 2 years of age to engage in comforting behaviors in response to their parent's distress (Dunn \& Kendrick, 1981; Radke-Yarrow, Zahn-Waxler, Richardson, Susman, \& Martinez, 1994). In an analysis of the conditional responding of family members to one another, Hops et al. (1987) found that the mother's depressive behavior served to lower the probability that the children and husband would emit aggressive behavior; similarly, the children's and husband's aggressive affect was found to suppress the mother's dysphoric affect. Using causal modeling, Hammen, Burge, and Stansbury (1990) found reciprocal associations between dysfunctional communication in the mother and negative self-concept and interactional behavior in the children. Snyder (1991) found support for a direct relationship between mothers' distress (self-reported negative mood and stress) and their 4- to 5-year-old sons' conduct problems as well as a mediating role of maternal discipline (more aversive behavior in response to the child's aversive behavior and giving in to the child's aversive behaviors). Finally, Goodman et al. (1994) found the expressed negative attitudes of mothers toward their children to moderate the association between maternal depression and children's lower global self-worth. In sum, researchers using statistical modeling and sequential analyses are beginning to provide support for a direct role of depressed mothers' inadequate parenting in the emergence of the children's maladaptive skills and styles.

The fourth component of Mechanism 3 maintains that, through social learning or modeling, children acquire cognitions, behaviors, and affect that resemble that displayed by their depressed mothers. In assessing the empirical support for this component of the mechanism, we examine three literatures. First, we examine evidence that children of depressed mothers themselves, even though essentially asymptomatic, are characterized by negative affect, behavior, and cognitions. Second, we assess correlational studies that examine similarities between depressed mothers and their children with respect to their affect, behavior, or cognitions. Third, we examine evidence that modeling or other social learning processes can explain the acquisition of these phenomena in the children.

Are children of depressed mothers characterized by negative affect, behavior, and cognitive functioning in the absence of explicit depressive symptoms? Children of depressed mothers have been found in several studies to differ from control children with respect to their negative affect and behavior. For example, compared with infants of well mothers and of psychiatric controls, infants of both subclinically and clinically depressed mothers have been found to be less responsive, less active, and less content; to have flatter affect; and to show less distress during maternal

\footnotetext{
${ }^{5}$ Patterson (1982) found an association between aggressive children and a higher incidence of depression in the mothers.
} 
separation (e.g., Cohn et al., 1986; Dawson et al., 1992; Field et al., 1985; Sameroff, Barocas, \& Seifer, 1984; Whiffen \& Gotlib, 1989; Zekoski, O'Hara, \& Wills, 1987; but see also Dawson, Frey, Panagiotides, Osterling, \& Hessl, 1997). Zahn-Waxler, Cummings, Iannotti, and Radke-Yarrow (1984) found that, compared with control children, 2-year-old children of depressed mothers exhibited heightened emotionality when exposed to conflict and distress in others, as well as a tendency to suppress their emotions as a way of coping with stressful situations. School-aged and adolescent offspring of depressed mothers have been found to have poorer peer relations and less adequate peer relations skills than have children of nondepressed control mothers (Beardslee, Schultz, \& Selman, 1987; Billings \& Moos, 1985; Goodman, Brogan, et al., 1993; Lee \& Gotlib, 1989, 1991a).

In contrast to the number of studies of affect and behavior in children of depressed mothers, surprisingly fewer empirical studies were found to have shown that children of depressed mothers also are characterized by negative cognitions. The presence of negative cognitions in children of depressed mothers might reflect modeling of their parents' negative thinking about themselves, or the experience of having been frequently criticized or reinforced for their own negative views of the world. Most frequently, studies of cognitive functioning in children focus on beliefs about the self. Compared with children of well mothers, 8- to 18-year-old children of unipolar depressed mothers have been found to have significantly lower self-concepts, to report a significantly more negative cognitive style, to be more self-critical and more likely to blame themselves for negative outcomes, and to be less likely to recall positive self-descriptive adjectives (Garber \& Robinson, 1997; Hirsch, Moos, \& Reischl, 1985; Jaenicke et al., 1987). Interestingly, Garber and Robinson (1997) found in a sample of 12-year-old children of mothers with a history of nonbipolar mood disorders that these negative cognitions were stronger in offspring of chronically depressed mothers, even after controlling for the children's own depression scores. In one exception to this general pattern, Goodman et al. (1994; Goodman, Brogan, et al., 1993) found no significant differences between 5- to 7-year-old children of mothers with a history of unipolar depression and children of well mothers with respect to the children's self-perceived competence or locus of control beliefs; 8- to 10-year-old children differed only on global self-worth.

Second, are the negative affect, behaviors, and cognitions of depressed mothers associated with similar behaviors in their children? Observational studies of the infants and young children interacting with their depressed mothers offer support for this part of the mechanism. In several studies, Field and colleagues (Field et al., 1990; Field, Healy, \& LeBlanc, 1989) found that infants of depressed mothers "match" their mother's negative state (interestingly, less matching was observed when the mothers were positive toward the infants). Breznitz and Sherman (1987) found that young children of depressed mothers match the low rates of speech of their mothers in conversations with them. Similariy, Breznitz and Friedman (1988) found that toddlers' duration of attention is negatively correlated with the frequency of their mothers' shifts in attention. Radke-Yarrow and Nottelmann (1989) found that toddlers and their depressed mothers display less mutually positive affect and more mutually negative affect than do nondepressed mother-child pairs, a pattern consistent with Hops et al.'s (1987) findings described earlier, in which the valence of family mem- bers' behaviors seemed to match that of the depressed mother. Moreover, Radke-Yarrow, Belmont, Nottelmann, and Bottomly (1990) found that negatively toned comments of depressed mothers were related to a measure of the children's negative selfschema. Somewhat contradictory with this pattern of findings was Jaenicke et al.'s (1987) finding that, during problem-solving tasks, mothers' and children's self-criticism levels were not significantly associated with each other. Interestingly, however, maternal criticism of the child during these tasks was significantly correlated with the children's self-critical comments during the tasks and with the children's self-blaming style on a self-report measure of attributional style.

Third, can the acquisition of these behaviors, affect, and cognitions in the children be explained by modeling or other social learning processes? The reviewed studies provided useful information. If children match their mothers' negative affect, behavior, and cognitions in the research settings, as they have been shown to do, they most likely also do so at home. However, although the evidence on children's matching of their depressed mothers' dysphoric affect, behavior, and cognitions is consistent with social cognitive theory, stronger support would come from tests of Bandura's (1986) tenets regarding variables that should influence the likelihood of modeling. For example, based on those tenets we would expect mothers to be stronger models for girls than for boys. In fact, two studies have demonstrated that depressed mothers may be more powerful models for their daughters than for their sons. Hops et al. (1990) found that 11- to 16-year-old daughters of depressed mothers exhibited more dysphoric affect and less happy affect than did younger (3-to 10-year-old) girls or boys of either age, and at levels similar to those displayed by their mothers. Similarly, Radke-Yarrow and Nottelmann (1989) found that daughters of unipolar depressed mothers were more likely to match their mothers' downcast mood than were their sons. These analyses of behavioral synchrony suggest the operation of early socialization of negative mood in daughters of depressed mothers to a greater extent than is the case in sons.

Another tenet that might be abstracted from Bandura's (1986) formulations is that boys would be expected more so than girls to model the anger-aggressive component of their mothers' depression, whereas girls would be more likely to model the behaviors more compatible with the stereotypical feminine gender role, such as dysphoric mood and ruminative thinking. We found no published reports of research testing this tenet. In an unpublished paper, Kochanska (1987) reported finding that although well women demonstrated the predicted pattern of being more tolerant and supportive of their sons' than their daughters' anger, the pattern was reversed for depressed mothers. Further research on this tenet is needed.

In sum, the data on children's matching of their depressed mothers' dysphoric and angry affect, behavior, and cognition support Bandura's social cognitive theory of how children of depressed mothers are influenced, whether through modeling, direct instruction, or performance outcomes. However, although these findings are consistent with a modeling or other social learning mediation mechanism, it is important to note that they are not inconsistent with other explanations.

The fifth and final component of Mechanism 3 maintains that the children's deficient skills and styles, and their acquired depressotypic cognitions, behaviors, and affect, place them at elevated 
risk for developing depression. That is, are these styles, cognitions, behaviors, and affect associated with an increase in the children's risk for the development of depression or other disorders? Some of the evidence relevant to this question comes from studies using samples unselected for level of maternal depression. For example, researchers have demonstrated that infants with lower vagal tone vocalize less, have less optimal neurological development, show less facial emotional reaction and expression, are less attentive to the environment, are less able to self-soothe, and have higher cortisol levels, suggestive of the experience of greater stress (e.g., Field, Pickens, et al., 1995; Porges, 1992; Porges, DoussardRoosevelt, \& Maiti, 1994); moreover, Portales, DoussardRoosevelt, Lee, and Porges (1992) found that inability to suppress vagal tone during attention-demanding situations at 9 months of age predicted behavior problems at 3 years. We noted above that Dawson and her colleagues found that infants of depressed mothers exhibit reduced left frontal brain activity. Other investigators have documented that this asymmetric pattern of lower left frontal activity is associated with a vulnerability to experience and express negative affect in stressful situations, with a tendency to withdraw and avoid interaction, and with lower behavioral initiation (Davidson \& Fox, 1988; Fox, 1994; Gotlib, Ranganath, et al., 1998). Finally, several investigators have found that negative affect is related to subsequent learning difficulties (e.g., Bugental, Blue, Cortez, Fleck, \& Rodriguez, 1992; Singer \& Fagen, 1992).

Focusing more explicitly on depression, investigators have found that compared with well mothers, depressed mothers use more negative and less productive communications with their children during a conflict task. Moreover, Hammen (1991) found that aspects of the mothers' communications with their children were significantly associated not only concurrently with children's diagnoses, behavior problems, social competence, and academic performance but prospectively with affective diagnoses at a 6-month follow-up.

With respect to children's negative cognitive functioning, it is not clear even in the general population whether these negative cognitions precede the development of depressive disorders and play a causal role in depression (cf. Barnett \& Gotlib, 1988; Gotlib \& Krasnoperova, 1998). In a meta-analysis of seven studies, Joiner and Wagner (1995) found moderate support for overall negative attributional style as a prospective predictor of increases in depressive symptoms in children. Only one study was found to have tested prospectively the predicted relation between negative cognition and subsequent depression in the children of depressed mothers. Hammen et al. (1988) found that, among children of depressed mothers, negative cognitions about the self (self-concept and negative self-schemata), but not negative attributional style, predicted adjustment problems at a 6-month follow-up assessment. No study has found that negative cognitions predict a diagnosis of depression in children of depressed mothers.

Finally, it is important to note that the presence of a mechanism linking the early stress of inadequate parenting and the subsequent development and expression of depression in the child is supported by results from animal studies. For example, Ladd, Owens, and Nemeroff (1996) exposed rat pups to the stress of separation from their mothers for $6 \mathrm{hr} /$ day from age 6 days to 3 weeks. The separated rat pups were found to produce twice as much CRF as did pups who were not stressed. Moreover, as adults, the rats that had experienced separation produced $25 \%$ more adrenocortico- tropic hormone (ACTH) in reaction to stress (a mild foot shock). Thus, rats stressed by maternal separation as pups were found as adults to overreact to stress. Ladd et al. proposed that the overproduction of CRF is related to hyperactivity of the HPA axis, which, in turn, is related to a predisposition to depression. It is important to note, however, that this pattern may not hold for childhood depression. Ryan and Dahl (1993) reported that, in at least some clinically depressed children (ages 8-12 years), ACTH may be down-regulated in response to CRF challenges, perhaps explaining the normal concentrations of cortisol that have been observed in depressed children and adolescents.

Summary. There is little question that depressed mothers are characterized by negative cognitions, overt behaviors, and affect. This depressive functioning not only renders the depressed mother an inadequate social partner for her children but, further, leaves her unable to meet her children's social and emotional needs. These unmet needs, in turn, limit the children's development of social and cognitive skills. Moreover, children of depressed mothers are clearly exposed to the mothers' depressive cognitions, behaviors, and affect. Consequently, these children, from infants through adolescents, have been found to exhibit cognitive functioning, affect, and behaviors that mirror broadly the depressed mothers' functioning. Although there are few studies that have examined the hypothesis that these negative behaviors, affect, and cognitions in offspring of depressed mothers are a precursor to the development of depression, there is intriguing evidence, from both human and animal studies, that this negative functioning in both the mothers and the children may indeed place the children at elevated risk for experiencing depression.

\section{Mechanism 4: The Context of the Lives of Children in Families With Depressed Mothers, Particularly the Stressors, Contributes Significantly to the Development of Psychopathology in the Children}

Researchers have documented a strong and consistent association between stress and depression in adults (e.g., Billings \& Moos, 1982; Gotlib \& Hammen, 1992; Hammen, 1988). Recently, investigators have attempted to elucidate the nature of this association by delineating more specifically different aspects of both stress and depression. For example, Hammen (1991) made an important distinction between dependent and independent stressors and, further, demonstrated that the negative life events experienced by depressed adults may actually be a consequence, rather than a cause, of their depression. Most relevant here is that children of depressed mothers are exposed not only to their mother's depression but also to a variety of stressors that are associated with the depression; it is the children's exposure to these stressors that is hypothesized in this mechanism to mediate the association between maternal depression and child psychopathology.

Empirical support. Because few researchers have examined contextual variables in their studies of children of depressed mothers, we know little about how children of depressed mothers deal with the relatively high number of stressors to which they are exposed. There is little question that children of depressed mothers are, in fact, exposed to a greater number of stressors in their lives than are children of nondepressed mothers. For example, Hammen et al. (1987) found that families with unipolar depressed mothers reported higher levels of stress than did families with medically ill 
mothers and families with well mothers. More specifically, families with unipolar depressed mothers reported more stress in the domains of marital and social relationships, job, finances, and relations with children. In addition, children in families in which there was a depressed mother reported significantly more episodic and chronic stressors than did children with well mothers (Adrian \& Hammen, 1990, reported in Hammen, 1991).

Perhaps the most pervasive stressor to which children of depressed mothers are exposed is parental marital discord. The association between marital discord and depression has been well documented (e.g., Bruce \& Kim, 1992; Crowther, 1985). Depressed persons' marital relationships have been consistently characterized as conflictual, tense, and hostile (e.g., Gotlib \& Beach, 1995; Kowalik \& Gotlib, 1987), and interactions between depressed women and their husbands are markedly negative (e.g., Hautzinger, Linden, \& Hoffman, 1982; Ruscher \& Gotlib, 1988). Although the direction of effect in the association between marital discord and depression is unclear (it is most likely to be reciprocal; cf. Gotlib \& Hooley, 1988; Hammen, 1992; Rutter \& Quinton, 1984; but see also Gotlib, Lewinsohn, \& Seeley, 1998), for the purposes of this article the important point is that children of depressed mothers are almost certainly exposed to high levels of marital conflict. Indeed, Gotlib (Gotlib \& Avison, 1993; Gotlib \& Lee, 1990) has argued specifically that the elevated marital discord associated with maternal depression may mediate the adverse impact of maternal depression on children.

Consistent with this formulation, Fendrich, Warner, and Weissman (1990) and Goodman, Brogan, et al. (1993) both reported data supporting the prediction that marital discord exacerbates the negative effects of maternal depression on child functioning. More specifically, among children with depressed mothers, those whose parents were divorced were more likely to be rated by their teachers as undercontrolled and lower on ego resiliency (Goodman, Brogan, et al., 1993) and to have a conduct disorder (Fendrich et al., 1990). Interestingly, investigators who have attempted to separate the contribution of marital discord and maternal depression to children's adverse outcomes have generally found that marital discord is more strongly related to children's problems than is maternal depression (e.g., Caplan, 1989; Cox, Puckering, Pound, \& Mills, 1987; Emery, Weintraub, \& Neale, 1982). Indeed, the consistency of this finding has led some theorists to suggest that heightened marital anger and hostility mediate the association between parental mental illness and children's psychological disturbance (e.g., Rutter \& Quinton, 1984).

Finally, a small number of investigators have examined stressors other than marital discord that might at least partially explain the adverse outcomes experienced by children of depressed mothers. For example, Belle (1982) and Pound, Cox, Puckering, and Mills (1985) reported that both maternal depression and stress associated with poverty were significant predictors of problems in the children. Similarly, Billings and Moos (1983) found that children whose depressed mothers reported high levels of stressful life events had more adjustment problems than did children whose depressed mothers reported low levels of stress. Hammen et al. (1987) found that both chronic stress and current depression (but not lifetime history of depressive disorder) uniquely contributed to the prediction of children's diagnostic status and behavior problems.

Summary. In sum, there is little question that children of depressed mothers are exposed not only to their mothers' depression but also to a more stressful environment than that experienced by children of nondepressed mothers. Despite the consistency of this general finding, little research has examined specifically the potential mediating role of stress in the association of maternal depression and the development of depression or behavior problems in the children. Indeed, few investigators have included contextual variables in their studies of the children of depressed mothers. One important caution that arises from a consideration of stress as a possible mediator of the association of maternal depression and adverse child outcome is that investigators who do not assess (or control for) stressors experienced by depressed mothers and their children may be overestimating the specific effect of the mother's depression on their children's difficulties. It may be that chronic stress should be treated as a separate and important predictor of outcome in children with depressed mothers (cf. Hammen, 1991). We return to this point in greater detail later in this article.

\section{Moderators}

What characteristics of children, the depressed mother, or the family, and what other aspects of the environment affect the nature of the association between maternal depression and negative child outcome? Is there support for factors that increase or decrease the risk for the child? Are there subgroups of children of depressed mothers who are at particularly elevated risk? In this section we address questions about the role of the father, critical periods, and level of "exposure."

\section{Moderator 1: Fathers May Increase the Risk for Psychopathology in Children of Depressed Mothers If They Are Absent or If They Also Have Psychopathology. Similarly, Fathers May Represent a Protective Factor If They Are Healthy, Involved, and Supportive}

Empirical support. Generally, the risk literature has documented the positive role of a supportive adult in increasing the resilience of children at risk for psychopathology (Garmezy, 1985; Werner \& Smith, 1980). Less attention has been paid more specifically to the role of healthy adults in the lives of children with depressed mothers. Indeed, studies that have included fathers have done so most typically to provide information concerning assortative mating. Assortative mating increases the likelihood that the spouse of a depressed mother also has a depressive disorder or another form of psychopathology (cf. Gotlib \& Hammen, 1992; Merikangas, 1984; Merikangas, Prusoff, \& Weissman, 1988). Consequently, children with a depressed mother are likely to also have a father with emotional disturbance.

There are several ways in which fathers could either exacerbate or attenuate the effects of maternal depression on child functioning. For example, a father with depression or some other disorder could increase the risk for psychopathology in the offspring through both genetic and environmental factors. On the other hand, healthy fathers who are involved in their children's lives could provide a positive role model for their children, as well as substitute or respite caregiving for the children; fathers could also offer support for the depressed mothers, who could then in turn provide better quality parenting to their children (Belsky, 1984). 
A number of researchers have obtained support for the prediction that the father's functioning may moderate the association between maternal depression and child dysfunction. Weissman et al. (1984) found that children with two depressed parents are at significantly greater risk for disorder than are children with one depressed parent. Goodman, Brogan, et al. (1993) found that fathers' psychiatric status, along with parents' marital status, explained a significant proportion of the variance in the social and emotional competence of 6- to 10-year-old children of clinically depressed mothers. Similarly, Conrad and Hammen (1989) found that the presence of a healthy father in the home was associated with lower rates of disorder among school-aged children of depressed mothers. Eiden and Leonard (1996) found that infants of mothers who were depressed and who also had partners who engaged in heavy drinking were even more likely to be classified as insecurely attached than were infants of depressed mothers whose partners did not drink heavily. Finally, Thomas and Forehand (1991) found that fathers' depression scores added small but significant unique variance, beyond that accounted for by maternal depression, in adolescents' teacher-reported emotional or behavioral problems.

- Carro, Grant, Gotlib, and Compas (1993) examined maternal and paternal characteristics at 1 month postpartum as risk and protective factors for children's internalizing and externalizing problems at 2-3 years of age. Although a low level of depressive symptoms in the husbands of depressed mothers was not found to function as a protective factor for the children's problems, fathers' depressive symptoms did serve to increase the mothers' depressive symptoms measured when the children were 2-3 years old. Thus, fathers' depression may affect the children indirectly by exacerbating the mothers' depression.

Some researchers have examined the processes by which the quality of the father's functioning may moderate the association between maternal depression and child functioning. Hops et al. (1987), for example, conducted sequential analyses on family interactions and found higher rates of caring behavior directed to 3- to 16-year-old children by psychiatrically well husbands of depressed wives than by psychiatrically well husbands of nondepressed wives. In a similar study with younger children, Hossain et al. (1994) found that nondepressed fathers had more positive interactions with their 3- to 6-month-old infants than did their depressed wives. Indeed, the well fathers were rated as significantly higher than the depressed mothers on scales of affective state, facial expressions, vocalizations, and game playing. The infants exhibited higher quality interactions with the fathers than with their depressed mothers. This finding suggests that husbands whose wives are depressed are attempting to compensate for the more negative behavior of their wives and are being more positive in their interactions with their children. Although Chabrol, Bron, and Le Camus (1996) failed to replicate these findings, they may have been hampered by a small sample size $(N=10)$ and relatively low levels of depressive symptoms in their sample.

Summary. Evidence is accumulating that fathers play an important role in families with depressed mothers, either exacerbating the risk of psychopathology in the child or protecting the child from the adverse effects of maternal depression. Although we found direct support for the moderating effect of the father in several studies, the results of other investigations suggest that the relation may be more complex. Transactional patterns were de- scribed from sequential observations both of family interactions in homes (Hops et al., 1987) and of infants interacting with their depressed mother and well father (Hossain et al., 1994). More studies will be needed to elucidate the nature of the role both of fathers who are well and of fathers who are emotionally distressed.

\section{Moderator 2: The Timing and Course of Mothers' Depression Will Moderate the Association Between Maternal Depression and Negative Outcomes in the Children}

Based on our general knowledge of child development, it is almost certain that first exposure to maternal depression will have a stronger and more negative impact when children are younger than when they are older. Although serious questions have been raised about the validity of the initial concept of a critical period (e.g., Turkewitz \& Devenny, 1993), research examining early physiological, affective, and cognitive development has indicated that these systems continue to develop rapidly over the first few years of life and that perturbations have consequences for subsequent development. For example, studies examining neurophysiological development have documented that the systems that are relevant to the regulation of arousal are functionally immature at birth and mature gradually during the first few years of life. More specifically, the lability of organismic arousal declines during the first year of life with the maturation of the HPA system and parasympathetic regulation (as indexed by vagal tone; Stansbury $\&$ Gunnar, 1994; Porges et al., 1994). At the same time, cortical inhibitory controls over arousal are gradually emerging (Dawson, 1994; Rothbart, Ziaie, \& O'Boyle, 1992). Thus, mothers' regulation of infants' emotions is needed most in this first year of life; the presence of postpartum depression may render depressed mothers incapable of providing this guidance.

Another consequence of early exposure to maternal depression is that it may be difficult for a young child to recover from the negative effects of a mother's depression; thus, the negative effects could continue through later periods of the child's development. Although the mother's depression is likely to remit, at least temporarily, we know little about malleability of the early physiological, cognitive, affective, and behavioral patterns acquired by the child. Moreover, given early negative effects of maternal depression, the child will have lost ground, relative to his or her peers, in the course of normal development (e.g., in the mastery of some stage-salient social skills), which will put him or her at a disadvantage (Hay, 1997; L. Murray \& Cooper, 1997). Similarly, the child may also have acquired a peer status (e.g., rejected or neglected) that is difficult to alter. Finally, dysfunctional behavioral patterns may be established, as may the beginnings of negative cognitive sets, beliefs, and so on.

A related matter in considering the relationship between depressed mothers and their children is that behavioral patterns that were adaptive for the children in the short term in dealing with the mothers' depressive episodes may generalize to other contexts, evolving into maladaptive behavior patterns. For example, a response pattern of withdrawal may be adaptive in the context of inconsistent, unresponsive, or harsh parenting that characterizes currently depressed mothers. However, the child might fail to discriminate improvements in the parent's behavior or to identify 
positive opportunities for interaction with other family members, peers, or other adults.

Finally, and implicit in this discussion, the second part of Moderator 2 maintains that a more chronic course of depression will have a more adverse impact on children's functioning than will a single episode of depression. As we noted earlier, depression is typically a recurrent disorder, with over $80 \%$ of depressed patients experiencing more than one depressive episode (e.g., Belsher \& Costello, 1988; Mueller et al., 1996). Nevertheless, in any sample of depressed mothers there will be considerable variability in course of the women's depression, and it is likely that the chronicity of the mother's depression will moderate its impact on the child.

Empirical support. Despite the strong theoretical and conceptual basis for Moderator 2, the empirical support is weak. With respect to the possible differential effects of earlier versus later exposure to maternal depression, no studies have compared children who vary in their age of first exposure. Similarly, few studies have tested the hypothesis that a chronic or episodic course of maternal depression will have more negative consequences for the children than will a single depressive episode. Sameroff, Seifer, Zax, and Barocas (1987) found chronicity to contribute to the prediction of developmental course in children with depressed mothers. Similarly, Campbell, Cohn, and Meyers (1995) found that women whose depressions were chronic from 2 months through 6 months postpartum had infants who were less positive during face-to-face interaction than did women whose depressions were episodic, although interestingly, chronicity was unrelated to security of attachment (Campbell \& Cohn, 1997). Beardslee and his colleagues (e.g., Beardslee et al., 1987; Keller et al., 1986) found that the chronicity of parents' affective disorder was related to lower adaptive functioning and higher rates of psychopathology in their adolescent children. In a related study, Hammen et al. (1991) reported a strong temporal association of maternal depression episodes and the child's diagnosis for 11 children who developed major depression.

Another group of investigators took a slightly different perspective on the proposed moderator, examining whether a reduction in the parents' depressive symptomatology results in a return to a normal level of functioning in the children. Field (1992) examined 6-month-old infants of mothers who had been depressed early in the infants' lives but were no longer depressed. Field noted that the infants no longer looked "depressed" at 6 months, nor did they exhibit cognitive delays or emotional symptoms at 12 months of age. Other researchers have reported more broadly that children's functioning improves when family adversities, not specifically parental depression, decrease (e.g., Cicchetti \& Schneider-Rosen, 1986; Pianta, Erickson, Wagner, Kreutzer, \& Egeland, 1990).

In contrast to these findings, however, several other longitudinal studies found that children of depressed mothers continue to have behavior problems following the mothers' recovery. For example, both Billings and Moos (1985), in a 1-year follow-up of children who had ranged in age from 3 to 18 years old, and Cox et al. (1987), in a 6-month follow-up of 2-year-olds, found that depressed parents who had remitted continued to report more dysfunction in their children than did the control parents, although less than the nonremitted group. Alpern and LyonsRuth (1993) followed low-income 4- to 6-year-old children whose mothers had been depressed when the children were 18 months old. These investigators found that regardless of whether the mother had recovered, children who were 18 months old at the time their mothers had been depressed had higher parent- and teacher-rated child behavior problems than did children of never-depressed mothers (unfortunately, there were no explicit comparisons of the continuously depressed with the recovered group). Similarly, maternal depression when children were 14 months old or younger has been found to predict preschool-aged children's behavior problems (Ghodsian, Zajicek, \& Wolkind, 1984) and 4-year-olds' lower cognitive ability (Cogill, Caplan, Alexandra, Robson, \& Kumar, 1986), regardless of the mother's depression status at followup. Stein et al. (1991) found that postpartum depression had a negative effect on 19-month-old children even when their mothers' depression had remitted. Finally, Lee and Gotlib (1991a) reported a 10-month follow-up of 7-to 13-year-old children of both depressed and nondepressed patients and community controls. Lee and Gotlib's results indicated that the group of formerly depressed women, despite a significant reduction in their depressive symptoms, continued to describe their children as having a greater number of behavior problems (both internalizing and externalizing) than did the nondepressed control mothers. Importantly, clinical interviews with these children also revealed high levels of mood symptoms and somatic complaints.

Finally, we should acknowledge the possibility that some of the correlates of maternal depression, such as the deficits in parenting by depressed mothers, marital distress, and so on persist beyond the depressive episode itself and may explain the residual difficulties in the children following the mothers' recovery. Consistent with this possibility, Stein et al. (1991) found that mothers whose postpartum depression had remitted continued to engage in less affective communication and sharing with their 19-month-old toddlers than did mothers with no history of depression. In contrast, however, Campbell and Cohn (1997) found no evidence of dysfunctional qualities of mother-infant interaction among mothers who were no longer clinically depressed, even if they were continuing to experience and exhibit low levels of depressive symptoms.

Summary. We found no studies that examined whether earlier exposure to maternal depression has more adverse effects on children than does later exposure. Results from the few follow-up studies are more relevant to the concern about whether infants and young children recover from deficits associated with early exposure to a depressed mother. For the most part, these studies found that although there is some level of recovery, the children do not function as well as children who had not had the early exposure. Moreover, although chronicity of maternal depression appears to be an important component of this model, it is clear that much more research is necessary to elucidate the impact on children of more chronic forms of maternal depression. Unfortunately, investigators examining the effects of maternal depression on child functioning rarely provide information concerning the course of the mothers' depression; similarly, there are virtually no studies that have treated chronicity of maternal depression as a variable of interest. Longitudinal studies would be most useful in this regard, given their relative independence from biases in retrospective reporting on course or in psychiatric history records. 
Moderator 3: Characteristics of the Children, Such as Temperament, Gender, and Intellectual and SocialCognitive Skills, Moderate the Association of Maternal Depression and Negative Child Outcomes

Transactional considerations raise the question of whether some children are more vulnerable than others to the interpersonal contexts of depression or to the biological risks associated with this disorder (i.e., the dysfunctional neuroregulatory mechanism described above). For example, children with easier temperaments are expected to be less vulnerable to the effects of the inadequate parenting that has been observed in depressed mothers (Bates, Maslin, \& Frankel, 1985; Cutrona \& Troutman, 1986). This decreased vulnerability is predicted to be a function of the children's lower sensitivity to change, higher threshold for stimulation, and more flexible response style (i.e., less reactivity to environmental challenges); such children are also less of a stressor to already stressed parents. More broadly, children may vary in stressresistance or coping styles, and these individual differences are hypothesized to moderate the biological, parenting, and stress exposure effects of maternal depression.

Empirical support. Unfortunately, we found no studies that lend support to this potential moderating role of temperament in the association between maternal depression and child dysfunction. Somewhat tangentially, some investigators have found that mothers' perceptions of their infants as being difficult to care for are associated with their levels of depression (Cutrona \& Troutman, 1986; Gotlib, Whiffen, Wallace, \& Mount, 1991). Clearly, this is a critical area for further research, particularly in light of recent findings suggesting a neuroregulatory basis for temperament (e.g., Kagan et al., 1988) and a predictive role of childhood temperament for adolescent psychopathology (e.g., Schwartz, Snidman, \& Kagan, 1996).

Another characteristic that has been proposed to moderate the association of maternal depression and child psychopathology is the gender of the child. Girls may be more vulnerable than boys to the effects of maternal depression because of gender role modeling, especially during adolescence (Hops, 1996). It is also possible that girls and boys are affected by maternal depression in different ways. For example, whereas daughters of depressed mothers may be more vulnerable to develop depression, sons of depressed mothers may be more likely to develop conduct problems (Cummings \& Davies, 1994). Furthermore, given the greater fetal and neonatal mortality in boys than girls, it is also possible that boys are more vulnerable than are girls to the hazards of the in utero environment. Finally, boys may have stronger biological reactions to stress than do girls, although this position is controversial (e.g., Emory, Schlackman, \& Fiano, 1996).

The findings on gender differences in psychiatric outcomes have been mixed. Research has shown that, in general, boys are at higher risk than girls for the development of psychopathology (Rutter \& Quinton, 1984), although this pattern may be reversed at adolescence (Petersen, 1988). Among investigators who have examined children of depressed mothers, most either did not report gender differences or reported them not to be significant (e.g., Hammen, 1991; Harnish, Dodge, Valente, \& Conduct Problems Prevention Research, 1995; Thomas, Forehand, \& Neighbors, 1995). And among those studies in which significant gender differences have been obtained with respect to the presence of psy- chopathology in the offspring of depressed mothers, some have found girls to be worse off than boys (e.g., Davies \& Windle, 1997; Fergusson, Horwood, \& Lynskey, 1995; Hops, 1996; Keller et al., 1986), while others have found boys to function more poorly than girls (e.g., Gross, Conrad, Fogg, Willis, \& Garvey, 1995; L. Murray, Fiori-Cowley, Hooper, \& Cooper, 1996; Sharp et al., 1995). Hay (1997) reported that in one sample of postpartum depressed mothers, depression was associated with lower cognitive scores for boys but not for girls; this pattern was not replicated, however, in another sample of postpartum depressed mothers.

It is likely that different models may be necessary to understand the differential risk to sons and daughters of depressed mothers. Hay (1997) suggested that infant boys may be more vulnerable than girls to mothers' noncontingent responsiveness and negative affect, as evidenced by their being more likely to develop insecure attachments (L. Murray, 1992). Klimes-Dougan and Bolger (1998) found differences in the coping strategies of sons and daughters of depressed mothers. K. T. Murray and Sines (1996) found that although both genetic and nonshared environmental factors accounted for significant proportions of the variance in children's depressive symptomatology, the relative contributions and the nature of the environmental factors differed for boys and girls.

A final possible moderator of the association between maternal depression and child psychopathology is children's intelligence or level of social-cognitive skills. Children of depressed mothers may be protected against adverse outcome concurrently and prospectively if they are more intelligent (Radke-Yarrow \& Sherman, 1990) or have better social-cognitive skills (Beardslee et al., 1987; Downey \& Walker, 1989). For example, Radke-Yarrow and Sherman (1990) found that among 5- to 6-year-old children of depressed mothers who were characterized by three protective factors (having above average intelligence, being socially engaging, and having a "special positive place in their families"), none met criteria for a psychiatric diagnosis. The 8- to 11-year-old children in the same families who had this set of protective factors were also less likely to have psychiatric disorder.

Two studies offer limited support for a role of social-cognitive functioning as a mediator of the association between maternal depression and child functioning. Beardslee et al. (1987) found that adolescents' interpersonal competence, measured by their social-cognitive capacity for mutualify in relationships, added a small but significant amount of explained variance in predicting their level of functioning, even after accounting for age, sex, IQ, parents' illness, and disorder in the adolescent. Unfortunately, the authors were unable to examine possible differential effects of the timing of parents' depressions and how that might be related to the adolescents' development of social-cognitive skills. In the second study, Downey and Walker (1989) found that interpersonal problem-solving competence and attributional and response biases of 9- to 14-year-old children reduced their risk of aggression and peer rejection, but only among the subset of children who were maltreated by their clinically depressed mothers.

Summary. The results of a relatively small number of studies offer limited support for the role of child temperament, gender, and intellectual and social-cognitive skills as moderators of the association between maternal depression and child dysfunction. Although some child characteristics are intriguing for their potential to function as protective factors, others such as low intelligence and poor social-cognitive skills may represent early manifestations 
of psychopathology in the children, the vulnerabilities in our model. For example, the poor attention and concentration associated with depression could contribute to lower IQ test scores. Similarly, children with poor social-cognitive skills are more likely to be rejected and may behave aggressively, thereby increasing their risk for psychopathology (Dodge, 1990; Rubin, Hymel, Mills, \& Rose-Krasnor, 1991). Thus, although there is preliminary support for the inclusion of these variables, and of child gender, in our model, the role of these variables is not yet clear, and alternative hypotheses must be tested.

\section{Issues and Recommendations}

In this article, we have proposed a model of the transmission of risk to children of depressed mothers. A major purpose of this model is to guide our understanding of the specific multiple processes that might explain the adverse outcomes of the offspring of depressed mothers, account for how these risk mechanisms might interact, and consider the role of development in the transmission of risk. In presenting this model we reviewed a large number of studies, many of which provided support for specific components of the model. In this section we raise and discuss four issues that we believe are particularly relevant to this model: (a) the strengths and limitations of the proposed mechanisms, (b) the level of theory that best serves this area of study, (c) the specificity of the model to depression in the mothers and as the adverse outcome to the children and the consideration needed for the potential role of specific correlates of maternal depression, and (d) the importance of the concept of sensitive periods and children's recovery from adversity. In presenting this discussion, we also offer specific suggestions for future research that we believe would be important in beginning to address and resolve these issues.

\section{Strengths and Limitations of the Proposed Mechanisms}

In assessing the relative strengths of the various components of the model of risk that we have presented in this article, we present an evaluation of the research described earlier in the context of the four risk mechanisms. Where possible, we examine the strength of the evidence that the proposed mechanisms mediate the association between maternal depression and psychopathology in the child. Although none of the mechanisms or moderators proposed in the model can be considered to have been supported conclusively, support for some components of the model is more robust than for others, and in this section we evaluate the strength of this support. We also discuss evidence for a developmental course of risk, whereby the effects of the mechanisms may be different for children of different ages, or as a related point, may be a function of the timing of the mother's depression. We turn now to a brief evaluation of the empirical support for the four proposed mechanisms of the transmission of risk to children of depressed mothers.

Genetics mechanisms. The genetics mechanism has received strong support with respect to both depression in adults (although not specifically for children of depressed parents) and the heritability of traits and environmental factors that increase vulnerability to depression. There is less clear support for the genetic contribution to depression that is postulated to emerge during childhood or adolescence among children of depressed mothers. In addition, although trait markers for depression in children have been pos- tulated, they have not yet been identified (Puig-Antich, 1984; Puig-Antich et al., 1983).

There are also a number of problems in the genetic approach to risk for depression that have not yet been resolved. Most important is that we do not yet know exactly what is inherited and how that inheritance might be manifested-answers to these questions are essential in attempting to understand the functioning of children of depressed parents. From a more methodological perspective, most of the family studies have used clinical samples, which could confound their results. That is, depressed mothers may be more inclined than nondepressed mothers to bring their depressed children for treatment (Goodman et al., 1997), biasing the findings toward increased rates of depression in the relatives. Studies of twins, adoptees, and step-siblings have the advantage of having sampled from an unselected population rather than from clinical samples. Nevertheless, these children and their families are not representative of the general population of children, which raises important questions concerning the generalizability of these findings (cf. Baumrind, 1993; Hoffman, 1985, 1994; Plomin \& Daniels, 1987).

Issues of reliability and validity of measurement are also particularly important with respect to genetic mechanisms of risk. It is critical, for example, that investigators develop reliable and valid measures of the environment of children of depressed mothers and critical that they use measures and classification procedures that have already been demonstrated to be reliable and valid in the assessment of depression in both parents and their children. Studies in this area have also varied widely with respect to the informant that they used to assess children's symptoms of depression, sometimes relying solely on the relatively insensitive parent report and, in any case, limiting the ease with which we can compare findings across studies (e.g., Angold et al., 1987). More broadly, investigators will need to examine genetic and environmental influences using experimental designs that overcome the weaknesses of established behavior genetics designs, for example, the "equal environments" assumption with respect to monozygotic and dizygotic twins and adopted and biological children (Hoffman, $1985,1994)$; investigators will also need to develop designs that are more sensitive to socialization models and environmental theory (e.g., Bronfenbrenner \& Ceci, 1994; Hoffman, 1985) and develop measures of family environment that are less dependent on questionnaires.

Finally, behavior genetics research designs typically ignore important developmental and transactional considerations. A separate analysis by the age of the children is not sufficient to address developmental concerns. Research is required that examines the potential of genetically based features to evoke particular environments, using bi-directional models. Longitudinal research is also needed to allow a consideration of developmental pathways through which differences among children (both genetically and environmentally influenced) influence the parents' behavior, and vice versa, in patterns that unfold over time.

Adverse prenatal experiences mechanisms. How strong is the support for the role of innate dysfunctional neuroregulatory mechanisms in the transmission of risk for depression from depressed mothers to their children? Overall, the support for this mechanism is mixed. There is evidence that depressed women have higher rates of abnormal pregnancies, especially with regard to the hypersecretion of CRF. However, no studies were found that exam- 
ined the placenta to determine the amount of CRF hypersecretion to which the fetus had been exposed. Nevertheless, it is also important to note that the results of a number of studies of infants born to women who had been depressed during pregnancy indicate that the babies are exhibiting abnormal functioning at birth. These studies are important because it is likely that they assessed the infants' functioning before any adverse consequences of exposure to the depressed mother had appeared, thus implicating more strongly the role of abnormal fetal environments.

Moreover, knowledge of the psychobiology of depression justifies concern for infants who, as fetuses, might have been exposed to CRF hypersecretion. We would expect that the consequences of such exposure would be manifested in abnormal stress reactivity, negative behavioral and affective functioning, and abnormal EEG patterns in the infant. Each of these aspects of functioning is known to be disrupted in adult depression (e.g., Davidson \& Fox, 1988; Gotlib, Ranganath, et al., 1998) and could conceivably represent markers of risk for depression in the infants (Field, Fox, et al., 1995). Therefore, further studies are needed examining the fetal environment, examining how it is associated with neonatal functioning, and assessing more explicitly and precisely how fetal environment and neonatal functioning might contribute to risk for the development of depression. It is also not yet known whether treatment for depression during pregnancy is associated with a return to the levels of biochemical functioning of nondepressed women, with the consequence that the neonate may be unaffected by what was previously a potentially hazardous intrauterine environment.

Adverse parenting mechanisms. There is consistent empirical support to indicate that depressed mothers expose their children to more negative cognitions, affect, and behaviors than do nondepressed mothers and that, in a number of ways, they are inadequate partners to meet their children's stage-salient needs. There is also consistent evidence to indicate that the children of depressed mothers themselves exhibit maladaptive cognitions, affect, and behavior. We have little understanding, however, of how the children of depressed mothers acquire these traits or tendencies, or of the extent to which these traits and behaviors might mediate their risk for depression.

Stronger support for this mechanism could be provided by examining the ways in which exposure to, and interaction with, a depressed mother might contribute to the child's development of negative cognitions, affect, and behavior. Alternative interpretations for the child's negative functioning, and especially genetic explanations, need to be ruled out or considered in an integrative model. For example, more information is needed concerning the relative frequency with which depressed mothers and other family members model and reinforce healthy and unhealthy cognitions, affect, and behaviors. The nature of the association between parents' negative cognitions, affect, and behavior and child outcomes would also be tested more directly with studies that are based more strongly on process-oriented models (Bronfenbrenner, 1986). In such studies, investigators would examine the extent to which, or level at which, a mother engages in the putative risk behavior (e.g., self-critical statements), and not merely whether the mother is depressed, with respect to her behavior's association with the children's demonstration of similar behaviors. The studies examining children's matching of their depressed mothers' affect and behaviors are important steps in the proposed direction.
Empirical support for this mechanism would also be strengthened by studies examining the prospective associations between the children's depressotypic cognitions, mood, or behavior and their subsequent development of depression. The findings reviewed earlier - that depressed mothers display more negative cognitions, affect, and behavior than do nondepressed mothers and that their children display more negative cognitions, affect, and behavior than do children of nondepressed mothers-are necessary but not sufficient findings to support the hypothesized mechanism. Following Baron and Kenny (1986), the hypothesized mediating roles of these constructs could be tested more explicitly in two phases. The first phase would involve tests of the following hypotheses, some of which have already been subjected to empirical examination:

Hypothesis A1: Elevated levels of maternal depression are associated with mothers' greater display of negative cognitions, affect, and behavior. Empirical support for this component of the mechanism is strong.

Hypothesis A2: Higher levels of negative cognitions, affect, and behavior in the mother are associated prospectively with higher levels of depression in the children. Support for this component of the parenting mechanism is currently weak. Although several studies have found that depression in mothers is associated prospectively with depression in their children, no study was found to have demonstrated that the depressed mothers' negative cognitions, affect, or behavior per se predict subsequent depression in their children.

Hypothesis A3: Controlling for A1 and A2, the strength of the association between maternal depression and children's depression is significantly decreased.

Similarly, the following hypotheses would be tested in the second phase:

Hypothesis B1: Elevated maternal displays of negative cognitions, affect, and behavior are associated with more negative cognitions, affect, and behavior in their children. Support for this component of the mechanism is strong.

Hypothesis B2: More negative cognitions, affect, and behavior in the child are associated prospectively with higher levels of depression in the child. Support for this component is weak. Only one study was found to have tested this component (Hammen et al., 1988), and it provided only limited support for this component. Moreover, investigators examining this hypothesis will have to work from a diathesisstress perspective, predicting children's subsequent levels of depression from an interaction of their negative functioning and a stressful life event (cf. Monroe \& Simons, 1991).

Hypothesis B3: Controlling for B1 and B2, the association between maternal depression and children's depression is significantly decreased. Research meeting these design criteria would have the potential of providing stronger support for the mechanism of negative cognitions, affect, and behavior in children (regardless of how they are acquired) in the transmission of risk for depression from depressed mothers to their children.

Finally, conducting more studies of older children, and particularly adolescents, would have the potential of providing stronger support for this mechanism. It is critical that we begin to examine precisely how mothers' depression may negatively affect the nurturance and control, authoritative discipline, and parental monitor- 
ing that have been linked to the social and intellectual competence and mental health of school-aged children (Baumrind, 1971; Maccoby \& Martin, 1983; Patterson, 1982). It will also be important to examine outcomes that might be particularly vulnerable for this developmental stage. This approach of examining stage-salient issues has yielded promising results in studies of infants and young children of depressed mothers, and the approach's extension to older children is clearly an important direction for future research.

Stressful context mechanism. The empirical support for this mechanism that proposes that the adverse consequences to children of depressed mothers are a function of exposure to stressful environments comes primarily from findings that children with depressed mothers face multiple stressors (Hammen et al., 1987). It is clear from the results of studies in other literatures, not specific to depressed mothers, that such stressors (e.g., marital discord, stressful events, financial strains) have negative consequences for children. What is not yet known, however, is the extent to which these stressors represent a mechanism through which children of depressed mothers develop adverse outcomes. Arguably, therefore, this mechanism represents the weakest and least specific link in the model with respect to empirical validation.

Indeed, none of the studies that examined stress in the families of children with a depressed mother directly tested a mediational model. In some studies stress was found to function as a moderator variable, increasing the strength of the association between maternal depression and negative child outcomes. The single exception to this general pattern was reported by Hammen et al. (1987), whose data supported an additive rather than a moderator model, with maternal depression and stress both having cumulative negative effects on child functioning.

Empirical support: Robustness of components. In sum, none of the specific mechanisms that we have delineated in this article has received unequivocal support by the empirical literature. Although many of the strongest findings for the model represent empirical support for specific components of the proposed mechanisms, little research has examined the mediational role specified by the mechanism. For example, an important component of each mechanism is the link between maternal depression and the mechanism. Across all mechanisms, this component was found to have strong support. Thus, we found maternal depression consistently to be associated with heritability of depression; with adverse prenatal experiences; with multiple aspects of adverse parenting in the domains of cognition, affect, and behavior; and with stressful life experiences.

The association between the mechanisms and the development of depression or other psychopathology in the children has received considerably less empirical attention. The genetics mechanism is one of the few for which relevant studies were available, that is, studies of the genetic contribution to childhood depression. Interestingly, the results of some of these studies indicate that there may not be a strong heritability component for childhood depression, at least in certain subsamples. The mechanism implicating adverse prenatal experience in the transmission of risk from depressed mother to child has received strong empirical support from the studies on nonhuman primates and rodents but has not yet been investigated in humans. The associations between the development of depression in the children and exposure to both adverse parenting and stressful environments have not yet received adequate empirical attention.
Finally, all of the proposed mechanisms have received at least some empirical support with respect to their association with the vulnerabilities described in the model. The genetics mechanism is supported by the findings of strong heritability for many of the environmental and personal characteristics that increase vulnerability to depression. The adverse parenting mechanism is supported by findings of a strong association between the adverse parenting of depressed mothers and skills deficits or maladaptive cognitive, affective, and behavioral styles or tendencies in the children. The adverse prenatal experiences and stressful context mechanisms have received less direct empirical support. Thus, a number of studies have reported a strong association between abnormal pregnancies in women experiencing stress, rather than depression per se, and abnormal functioning of the neonate. Similarly, support for the stressful context mechanism comes from studies that examined the consequences for children of exposure to various stressors but that were not specific to maternal depression.

More broadly, research relevant to the key component to establish mediation, the functional roles of the mechanisms, has not yet been conducted. We rarely found studies that directly tested mediation as a causal mechanism, either statistically using correlational data (Baron \& Kenny, 1986; Holmbeck, 1997) or as a function of experimental manipulations, such as prevention experiments. These studies are clearly important, not only because they have the potential to provide support for the mechanisms proposed in this article but also because they may fail to confirm hypotheses, thus allowing for determination of the falsifiability of a putative mechanism.

It is also important to examine the extent to which the mechanisms are associated with adverse outcomes in the children. In this context, the concept of "dosage" might be helpful. For example, with respect to genetics, the number of first- or second-degree relatives with depression is likely to be an important variable. Similarly, the extent of exposure to self-critical statements or mother's sad affect, and the degree of adversity in the environment, may be important with respect to the parenting and stress mechanisms. Quantitative examinations of these aspects of the mechanisms proposed in this article could address such questions as, "How much exposure to (self-) critical statements is needed to result in specific negative effects on the child's cognitions and affect?"

Finally, when investigators examine the mechanisms proposed in this article, it will be important that they examine the functioning of clinically depressed women and their children, rather than rely on the more commonly studied samples of women who obtain high scores on self-report depression symptom or mood scales. We have noted the critical importance of this distinction throughout this article, and it is further underscored by Harrington et al.'s (1996) recent review of epidemiologic and adult outcome differences between depression as a mood feature and depression as a diagnostic category. For example, Harrington et al. reported that $84 \%$ of children who had a full depressive syndrome in childhood had the same syndrome in adult life. In contrast, although there was also strong continuity at the symptom level, at both age periods depressive symptoms were associated with a wide range of psychopathology other than depression. That is, depressed mood appeared to be a nonspecific indicator of psychopathology. In another set of studies, Harrington et al. reported that the age and gender trends that were found to characterize the diagnostic cate- 
gory of depressive disorder did not apply to findings derived from questionnaire measures of depressed mood. Summarizing these findings, Harrington et al. concluded that a diagnosis of depression is different in a number of important respects from depression as measured by questionnaires.

\section{Level of Theory}

In a sense, each of the proposed mechanisms offers a minitheory of how depressed mothers affect their children. Similarly, each of the proposed moderators offers a mini-theory of the circumstances under which children might be more or less affected by maternal depression. Indeed, most of the literature examining the effects of maternal depression on child functioning has taken the approach of studying one particular aspect of this association and, sometimes, generating small-scale theories focused on the particular processes under study.

In contrast to this approach, we argue strongly for the advantages of the additional explanatory power that comes from a model that provides a larger, more integrative picture of the transmission of risk from depressed mothers to their children. The more molecular approach, we believe, leaves us in a situation like the proverbial blind men and the elephant, in which each man, having touched a different part of the creature (e.g., a leg versus the trunk versus the tail), erroneously generalized from that experience to an innaccurate conceptualization of the elephant's true nature. The approach leads to difficulties associated with reductionism and dualism (e.g., biological versus psychosocial functioning). In contrast to these more restrictive perspectives, the model proposed, described, and evaluated in this article provides guidelines for exploring how the mechanisms interrelate and thus yields unique predictions. In this context, many theorists in psychology have been moving toward merging previously separate, narrow foci in attempts to provide stronger explanations of behavior. In particular, theorists are increasingly combining diverse biological and environmental processes and emphasizing their dynamic interplay (Zahn-Waxler, 1996). Transactional, multifaceted models have been the hallmark of much of recent research on developmental psychopathology. Unfortunately, measurement and research design become more complicated as researchers attempt to test those complex models. The model proposed in this article poses similar challenges; suggestions for relevant and illuminating research are unlikely to involve studies that are quickly and easily implemented.

That said, the integrative model presented in this article does raise important questions concerning the possible interrelations among the mechanisms. For example, does each aspect or component of the nonoptimal parenting mechanism operate as "stress" in a stress-diathesis model? If so, what are the diatheses? Possibilities that are suggested by the model include psychobiological vulnerabilities, such as lowered vagal tone, abnormal stress response, reduced left frontal activity, or genetically influenced tendencies, such as behavioral inhibition and negative affectivity.

From the broader perspective of the integrative model, it is apparent that the genetics studies that we reviewed are limited by their exclusive focus on attempting to estimate how much heritability contributes to individual differences. It is clear that the field of behavior genetics studies has the potential to make much greater contributions than it has to date to the understanding of the functioning of children with depressed mothers (Rutter, Silberg, \& Simonoff, 1993). For example, it is essential that any integrative model of the transmission of risk to children of depressed mothers include the genetic contribution to the experience of stressful life events and other aspects of the family environment that have been firmly established as significant correlates of parental depression. Moreover, as suggested in our model, studies are needed that explore gene-environment covariation, including the possibilities that siblings may be treated differently by the same depressed parent, that children of depressed parents may both seek and evoke certain qualities in their environments, and that at-risk children may "experience" their environments differently than do children of well parents. Although we found some support for the first of these possibilities, the latter two possibilities have yet to be explored systematically.

In gaining a more comprehensive understanding of the functioning of children of depressed mothers, it will also be important to identify exactly what it is that these children inherit. In this context, one promising research direction would be an integration of the conceptualization of biological trait markers with recent formulations concerning inborn neurobiological mechanisms. In an integrated model, there are two alternative pathways for the influence of biological trait markers that represent a vulnerability to depression: (a) The vulnerability manifests itself in behavior only in the context of maladaptive environments (e.g., inadequate parenting of infants; stress or hormone fluctuations during adolescence), or (b) the vulnerability is expressed in behavioral traits or tendencies that are evident at birth and that then become part of evocative, gene-environment correlations (e.g., the children engage the environment less actively or less positively; children selectively attend to, or are more sensitive to, negative aspects of their environment).

The first pathway, that vulnerability manifests itself only in maladaptive environmental contexts, is compatible with promising gene-environment interaction models, such as the stress-diathesis model (e.g., Monroe \& Simons, 1991). Walker et al. (1996) explicated a relevant model that focuses on the moderating role of stress exposure and reactivity (i.e., biological stress responses) in the expression of the organic diathesis for schizophrenia. The stress-diathesis model, approached with a consideration of developmentally sensitive time periods, suggests, for example, that maladaptive early parenting could result in the behavioral manifestation of a biological vulnerability in infants that would otherwise have remained unexpressed. Similarly, offspring who, by adolescence, have not yet manifested signs of illness, could experience a "turning on" of the biological vulnerability, perhaps through hormonal influences or through the accumulation of stressors. Indeed, this model may help to explain the potential role of genetics in contributing to the increased prevalence of depression that emerges for girls at puberty (cf. Hayward, Gotlib, Schraedley, \& Litt, 1998).

Even less is known about how the second pathway, geneenvironment correlations, might function in children of depressed mothers. If biological vulnerabilities can be measured reliably, it will be possible to test whether children with these vulnerabilities are more sensitive to the effects of environmental stressors than are their nonvulnerable counterparts. In general, we know little about how the relative importance of genetic and environmental risk factors might change over the course of development. From a 
genetic perspective, research designs that take advantage of psychiatric or twin registries, such as those used by Crowe (1975), Cloninger and his colleagues (e.g., Cloninger, Sigvardsson, Bohman, \& von Knorring, 1983), and Kendler and Kessler and their colleagues (e.g., Kendler et al., 1993), would be useful in examining whether genetically vulnerable children are more susceptible than others to adverse environmental stressors, and those research designs would enable researchers to test for variations in such associations in children at different periods of development.

To date, no studies have tested the more specific hypothesis of concordance for depression in offspring of affected (i.e., depressed) and unaffected monozygotic twins. Such research would help to delineate the developmental course of offspring who share the genetic risk of their cousins with a depressed parent but who may not experience the family environment correlates of parental depression. Indeed, the extent to which the unaffected twin-parent provides similar or different family environment experiences for his or her offspring is itself an unaddressed empirical question.

Other interesting questions arise regarding the processes that might unfold as a function of being born with greater or lesser genetic vulnerability to depression and of then being raised by a mother who experiences depression at some point(s) in the child's life. Weissman (1988), for example, suggested that whereas offspring of depressed mothers may follow a genetic pathway to depression, children of nondepressed mothers who become depressed may follow an environmental (family risk factors) pathway. To date, however, this thesis has not been examined empirically.

Another hypothesis concerning multiple mechanisms of transmission of risk suggested by the integrative model presented in this article is that cognitive-interpersonal influences, or more specifically, parenting behaviors, may be stronger determinants of children's functioning for those children who are not at the extremes on either genetically or prenatally caused behavioral traits or regulatory styles. At the extremes, it is likely that parents are less influential in determining their children's outcomes (Calkins, Fox, \& Marshall, 1996; Deiter-Deckard \& Dodge, 1997). Conversely, the extremes of parenting or the caregiving situation (e.g., abuse) will, in general, override the importance of children's characteristics, conferring vulnerability even to children without genetic or prenatal risks (Calkins, 1994).

It will also be important to determine whether supportive parenting might modify the risk for the development of depression in high-risk children who are identified early as having any of the hypothesized neurobiological vulnerabilities. For example, Thompson (1994) and Calkins (1994) suggested that risk for psychopathology may be reduced through a number of means, such as direct interventions for parents aimed at reducing negative emotions, modeling or selective reinforcement of the children's expressions of positive emotions, verbal instructions concerning positive emotion and emotion regulation strategies, and limiting the demands on the child early on in order to reduce the probability of negative emotional arousal. Importantly, depressed mothers have already been found to be deficient in several of these parenting supports. For example, compared with their nondepressed counterparts, depressed mothers make more negative attributions about their children during mother-child interactions (RadkeYarrow et al., 1990) and use more guilt induction and anxiety induction as discipline practices, thereby likely increasing their children's feelings of responsibility, guilt, and helplessness.

Studies are also required that explore how the four mechanisms proposed in this article might interact in conferring risk to children of depressed mothers. For example, the neuroregulatory dysfunctions that have been found at birth in the infants of depressed mothers have important implications in light of predictions generated by the parenting mechanism, providing more opportunities for exploring the integration of these two mechanisms. Children who look "depressed" (i.e., are lethargic, affectively flat, and irritable) likely require more arousing stimuli to elicit responses, and they are less likely to actively engage their environments, to focus their attention on learning opportunities, to cope with stress, and to evoke positive responses from their parents and peers. Moreover, given the characteristics of negative cognitive biases, such children are likely to selectively attend to negative aspects of the environment, to experience elevated levels of stress and sadness, and to withdraw rather than use active social or cognitive strategies for coping (cf. Gotlib \& MacLeod, 1997), thereby also implicating cognitive mechanisms in the transmission of risk.

Other examples of questions that cut across a number of these mechanisms are those being explored by Dawson and her colleagues concerning the influence of early adverse parenting on psychobiological vulnerabilities (e.g., Dawson et al., 1997; Dawson et al., 1994), and by Porges, Fox, and their colleagues (e.g., Fox, 1994; Porges, 1992; Porges et al., 1994) examining how infants' vagal tone might be related both to their emotion regulation abilities (e.g., their abilities to self-soothe and to explore novel stimuli) and to the likelihood that they will have behavior problems 2 years later. With respect to the latter question, the presence or relative strength of one or another mechanism may predict whether the child develops depression or, for example, conduct disorder. We discuss this issue of differential outcome in greater detail below.

The model also highlights the need for studies that examine the transactional aspects of the proposed mechanisms. More specifically, investigations are required that examine how the mediators are likely to interact and feed back to one another over the course of development. For example, although dysfunctional cognitions have been linked to behaviors that increase risk for depression, these associations have not been examined systematically in the offspring of depressed parents. Studies are also required that assess how the vulnerabilities of the offspring feed back to the parenting system, perhaps increasing the parents' stress, decreasing their sense of parenting efficacy, and adversely affecting the quality of parent-child interactions.

Another example of work that might benefit from the integrative model presented in this article is the research on neuroregulatory difficulties in infants with depressed mothers. Field and Dawson and their colleagues have found that infants of depressed mothers have lower vagal tone and reduced left frontal activity, important indexes of vulnerability to depression. An "environmental" interpretation of these two findings would be that they both reflect the negative effects of the stress of interacting with a nonresponsive, less synchronous, or irritable depressed mother. It is important to note, however, that these findings are also consistent with the operation of other mechanisms, such as genetically based or in utero environmental-based physiological differences in neural regulation. With either of the latter mechanisms, the deficit or dia- 
thesis either could become manifest only under the conditions of experience with a depressed mother or, alternatively, could be exacerbated by those experiences. Exploration of such transactions among mechanisms is likely to be much more profitable than further efforts to determine whether adverse parenting or preexisting biological vulnerability provides a stronger explanation for the neuroregulatory difficulties observed among children with depressed mothers.

Other similar questions are suggested by the moderators in the model. For example, as we reviewed above, several investigators have found that the specific stressor of marital discord is related to children's difficulties more strongly than is maternal depression (cf. Lee \& Gotlib, 1991b). Nevertheless, more research is required examining how marital conflict and parental depression may interact in ways that are related to the emergence of psychopathology in the children. In this context, Gottman's (e.g., Gottman et al., 1996) recent work on meta-emotion represents a potentially useful direction.

Finally, the integrative model presented in this article also provides a conceptual context within which to consider bidirectional influences. More specifically, the moderators described in this model could be tested for bi-directional effects. For example, research is clearly required examining children's influences on their mothers' depression. There have been some suggestions of such bi-directionality in mothers of infants who are difficult in temperament, whereby the infant might contribute to or exacerbate the mother's depression (Cutrona \& Troutman, 1986). The model raises other questions about how children with the particular vulnerabilities might affect their parents and others, who then influence the child in a dynamic interplay. Although some studies have examined such dynamics in a molecular way, such as the mother-infant studies or Hops's (1996) study of behavioral contingencies in family interactions, none has explored the longitudinal associations.

\section{Specificity of the Model to Depression}

There are two important aspects to the issue of specificity: the specificity of maternal depression as a risk factor for child depression and the specificity of child depression as an outcome of the impact of maternal depression. And even within this issue of the specificity of maternal depression as a risk factor, there are questions concerning the impact of depression versus other forms of psychopathology and the impact of depression versus confounded correlates of depression. There is little question that forms of psychopathology other than depression are associated with adverse outcomes in the offspring. Indeed, the field of high-risk research arguably began with the study of the effects of schizophrenia in the parent on children (e.g., Mednick \& Schulsinger, 1968) and has since included investigations examining the impact of parental depression, anxiety, and alcoholism (cf. Gotlib \& Avison, 1993). Much less research has examined the extent to which the mother's depression per se, rather than specific correlates of maternal depression, affects the children. Among the common correlates of depression that require consideration are poverty, co-occurring (or comorbid) disorders such as alcohol or drug abuse, general negative affectivity, marital conflict, and other stressors.
One correlate of maternal depression that has been studied more broadly than others is marital conflict. Thus, for example, as we noted earlier, Grych and Fincham (1990) and Katz and Gottman (1993) presented data indicating that marital conflict in the parents results in increased hostility and decreased availability of the parents to their children, which in turn increases the risk to the children for both internalizing and externalizing behavior problems. However, this formulation has not been examined explicitly among children of depressed parents. As we discuss in more detail below, if these findings are replicated among families with depressed mothers they would also have implications for the issue of the breadth or specificity of the effects on the children.

The relative impact of another important correlate of depression, poverty, has not been examined directly. Indeed, because poverty and depression have been confounded in previous studies, it is virtually impossible to examine differential effects of these two variables. In addition, in many of the studies in which depression is confounded with poverty, both these variables were also confounded with ethnic minority status. For example, both Field and Lyons-Ruth, who have made major contributions to the study of the impact of maternal depression on offspring, included a large proportion of ethnic minority women in their samples of lowerclass depressed women. It is very difficult in such studies to test the relative contribution of maternal depression, poverty or stressors associated with poverty, and belonging to an ethnic minority to adverse consequences for the children.

Clearly, therefore, future studies should include an explicit assessment of critical correlates of depression, ideally sampling across these correlates to permit testing of their relative contribution to the child outcome, both alone and in interaction with maternal depression. A consideration of these correlates is also important in the choice of control or comparison groups. Without assessing correlates of maternal depression, it is likely that group comparisons are overestimating the impact of the mother's depression. An example that nicely illustrates this point is Hammen's (1991) finding that stress should be treated as a separate and important predictor of outcome in children with depressed mothers. Ideally, future studies will provide a more complete understanding of the extent to which maternal depression exerts a unique impact on the children.

The second aspect of this issue, the question of specificity of outcome to the children, has also received little attention. It is important that a comprehensive theory ultimately be able to account for alternative outcomes in children of depressed mothers. Although a higher proportion of children of depressed mothers develop depression than is the case for children of nondepressed mothers, researchers have also documented higher rates of externalizing disorders among children of depressed mothers (cf. Hammen, 1991; Lee \& Gotlib, 1989); indeed, researchers have described some children of depressed parents, as young as infants, as angry rather than withdrawn (e.g., Cohn \& Campbell, 1992; Field et al., 1990). The reasons for this anger are not yet well understood, but it seems reasonable to hypothesize that it might be a function of the frustration that infants and children likely experience in not having their needs met by their depressed mothers.

Some theorists have speculated about specific conditions under which these outcomes might vary and have considered such factors as heredity, particularly with respect to the mother's comorbidity of depression with other psychiatric disorders, the overlay of 
marital problems, the age of the child when first exposed to the mother's depression, and the other moderator variables in our proposed model. For example, the varying outcomes in the children may be explained by heritability that is not specific to depression. Thus, children with depression and disruptive behavior disorders or substance abuse disorders may have relatives who themselves have had depression that is comorbid with alcoholism, substance abuse, or antisocial personality disorder (e.g., Kovacs et al., 1997; Williamson et al., 1995).

Diverse outcomes in the children could also reflect a different relative contribution of genetic and environmental influences. For example, Fendrich et al. (1990) found that among 6- to 23-yearolds of depressed parents, parent-child discord and low family cohesion were significant predictors of conduct disorder but not of any other psychiatric disorder. Findings such as these can be interpreted as suggesting that externalizing disorders in the offspring of depressed parents represent the expression of the genetic risk when it is combined with the relatively high rates of environment risks that exist in families with depressed mothers. It is important that Fendrich et al.'s finding be replicated in a sample with a narrower age range and with risk factors that follow from a conceptual model, such as that presented here. It is also important to rule out the bi-directional effect of the child on the parent or on the risk factors, for example, that more of the variance in parentchild discord is due to the child's conduct problems than to the depressed parent per se.

Another clue to specificity of outcome of children of depressed mothers comes from the finding of a number of studies that depression and externalizing disorders might share common biological underpinnings. For example, McBurnett et al. (1991) found that the cortisol levels of 8- to 16-year-old boys with pure anxiety disorders were no higher than were those of control children. In contrast, boys with both anxiety and conduct disorders had elevated cortisol levels relative to the other clinically diagnosed participants. Thus, HPA reactivity in childhood may be related to negative affect more broadly, rather than only to those negative affects that are associated more specifically with unhappiness and anxiety.

It is also possible that these various outcomes are a function of the frequent co-occurrence of depression with marital discord and its associated increase in interparental and parent-child hostility and decreased parental availability (cf. Lee \& Gotlib, 1991b). We discussed above the importance of examining marital discord in the context of assessing correlates of maternal depression, but it is likely that marital discord also affects the specificity of child outcome. Earlier in this article we described studies demonstrating that children's problems are related more strongly to parental marital discord than to maternal depression (e.g., Caplan, 1989; Cox et al., 1987; Emery et al., 1982); we also described studies indicating that marital discord increases the risk for both internalizing and externalizing behavior problems in children (e.g., Grych \& Fincham, 1990; Katz \& Gottman, 1993). Studies of depressed mothers who vary in the presence of discord in their marriages would illuminate the relative contribution of depression and marital discord to both conduct disorder and depression in their children (Downey \& Coyne, 1990).

Finally, our model provides reason to consider that the other moderator variables, in addition to child's age or timing of the exposure, may also help to explain different outcomes for children of depressed mothers. For example, antisocial personality disorder in the fathers of children with depressed mothers could increase the likelihood of disruptive behavior disorders in the children, either alone or comorbid with depression (e.g., Lahey et al., 1988). Other characteristics of the children such as their temperament, gender, and intellectual and social-cognitive skills could also influence their outcome. For example, Cummings and Davies (1994) implicated gender role modeling as an explanation for what appears to be an increased vulnerability to depression among daughters of depressed mothers and an increased vulnerability to conduct problems among their sons.

In general, from a methodological perspective, if child depression is the only outcome that is studied and if maternal depression status is the only predictor variable, the opportunity to determine whether adverse consequences to the children are specific to maternal depression is missed. Moreover, the onset of depression (or of any other disorder) is typically marked by specific antecedents, such as the vulnerabilities that are proposed in this model. In this context, research would also benefit from studies that examine vulnerabilities as intermediate outcomes, testing whether they mediate the association between the mechanisms and psychiatric or emotional outcomes. It will be particularly important to test whether specific mechanisms, or particular combinations of the mechanisms, are associated with specific vulnerabilities and, if so, whether those vulnerabilities are associated with specific outcomes for the children. Finally, studies that predict which children will remain well despite the presence of the putative mechanisms (and vulnerabilities) will be critical in understanding the processes involved in translating risk into overt psychopathology.

\section{Sensitive Periods and Recovery From Adversity}

The final issue we raise and discuss here concerns the concept of critical ages, or sensitive periods, and the possibilities for children to "recover" from the adversities associated with maternal depression. This issue arises from our concern that our proposed model of the transmission of risk (a) be sensitive to development and (b) be able to explain how risk might differ for children at different ages and explain how the transactional relations between risk and the emergence of psychopathology unfold over time.

The issue of the timing of the child's exposure to parental depression clearly requires further investigation. Studies such as that conducted by Alpern and Lyons-Ruth (1993) need to be replicated and extended to gain a better understanding of the importance of maternal depression that occurs early in a child's life. For example, it might be possible to examine the impact of this type of maternal depression by studying a high-stress sample of women who are at elevated risk for depression, such as women living in poverty. A significant proportion of such a sample of women would be expected to become depressed within, for example, 5 years. Thus, comparisons could be made among children whose mothers were never depressed in their first 5 years of life, children whose mothers were depressed early in their lives but had recovered at the time of assessment, and, most importantly, children whose mothers were not depressed in their first year of life but who became depressed thereafter. The roles of adverse parenting and other stressors would also be illuminated through studies of children who are similar in familial loading for depression but who vary with respect to the age at which they were first 
exposed to maternal depression. For example, by the age of 8 or 9 , children have formulated fairly stable self-perceptions and attributional beliefs (Digdon \& Gotlib, 1985; Harter, 1983; Seligman \& Peterson, 1986) and, therefore, may be less vulnerable at this age to a first exposure to a depressed parent's depressotypic cognitions and criticisms.

The older child or adolescent also requires special consideration. One important issue involves an interesting variation on the confound between environmental and genetic contributions to risk. More specifically, if a mother experiences a first onset of depression when her child is an adolescent, it is likely that the mother will be older than are mothers who become depressed when their children are infants or toddlers. In this context, it is important to note that age of onset for depression is significantly associated with familial loading (Weissman et al., 1984). Thus, the older the child when first exposed to parental depression, the less the environmental exposure and the less the genetic (and in utero environmental) risk to that child. It is clear that we require studies of children who are older when they are first exposed to their mother's depression and who differ on familial loading for depression. Given that the median age of onset for depression in women is 23 years (Burke, Burke, Regier, \& Rae, 1990), that is, in the midst of childbearing years, it should be possible to identify samples of children who vary with respect to the age at which they were first exposed to maternal depression.

The age of the child is relevant not only in terms of the timing of the parent's depression, but also more broadly, with respect to the developmental tasks faced by children at various ages. As we discussed earlier, infants are particularly vulnerable to the effects of maternal depression at least in part because their neuroregulatory mechanisms are still developing. It is important to be cognizant of the fact that although these mechanisms may be most strongly influenced during the period in which there is still considerable plasticity, once affected they will continue to have an impact on further development. That is, once they are affected, the operation of inadequately functioning neuroregulatory mechanisms has critical implications for subsequent functioning. We are just beginning to understand how these early alterations may result in permanently reduced adrenocortical responses to subsequent stressors (cf. Heim, Owens, Plotsky, \& Nemeroff, 1997). Such children would be expected to exhibit a state of sensitization to stress; ultimately, this vulnerability would be predicted to lead to an increased risk for development of depression. In a similar manner, children who acquire dysfunctional cognitions as a consequence of early exposure to maternal depression may have difficulty altering those negative beliefs even after the mother recovers from depression. Finally, children who withdraw from their peer group and later attempt to re-enter the group may have missed critical opportunities to learn social skills and may not be readily "re-accepted" by their peers.

Adolescent offspring of depressed parents also offer important opportunities for testing hypotheses generated by our proposed integrative model. Rates of depression increase at adolescence for offspring of depressed parents, as they do in the general population. It is not known, however, whether this increase reflects a "switching on" of the genetic vulnerability to depression or an interaction of genetic vulnerability either with pubertal onset or with the increased stressors of that time period. Thapar and McGuffin's (1996) finding of greater heritability of adolescent than of childhood depression needs to be considered within this context. Tests of the interactions of parental depression with offspring age and pubertal status would elucidate whether children with depressed parents are at increased risk for adolescent-onset depression. In this context, further exploration of the increased risk of depression for girls would also be important.

Another avenue that must be pursued with regard to the timing of the mother's depression concerns the differential effects of various "clusters" or subtypes of maternal depressive symptoms on children of different ages. That is, it would be important to know whether the predominant symptoms of a depressed mother, whether they be depressed mood, somatic concerns, or negative cognitions, have a more negative influence on the adjustment of younger children than on the adjustment of older children. Mediational models could be tested as well, such as whether a depressed mother's inadequate monitoring and discipline of her child is mediated by the mothers' negative view of herself as a parent (e.g., Jaenicke et al., 1987; Kochanska, Radke-Yarrow, et al., 1987; Teti, Gelfand, \& Pompa, 1990; Webster-Stratton \& Hammond, 1988). In general, increased developmental competencies may work both to children's advantage (increased ability to understand a stressful situation) and to their disadvantage (increased vulnerability to negative cognitions with age). It remains for future research to examine this issue more explicitly.

\section{Summary}

In this article, we proposed a developmentally sensitive, integrative model for understanding the mechanisms and moderators that might underlie the transmission of risk for psychopathology and abnormal development in children of depressed mothers. In presenting this model, we examined and evaluated empirical findings with respect to the extent to which they support each of the proposed mechanisms and moderators. We concluded by raising and discussing four issues that confront the field and by suggesting promising directions for future research in this area.

\section{References}

Abrams, S. M., Field, T., Scafidi, F., \& Prodromidis, M. (1995). Newborns of depressed mothers. Infant Mental Health Journal, 16, 233-239.

Alpern, L., \& Lyons-Ruth, K. (1993). Preschool children at social risk: Chronicity and timing of maternal depressive symptoms and child behavior problems at school and at home. Development and Psychopathology, 5, 371-387.

Angold, A., Weissman, M. M., John, K., Merikangas, K. R., Prusoff, B. A., Wickramaratne, P., Gammon, G. D., \& Warner, V. (1987). Parent and child reports of depressive symptoms in children at low and high risk of depression. Journal of Child Psychology and Psychiatry and Allied Disciplines, 28, 901-915.

Bandura, A. (1986). Social foundations of thought and action: A social cognitive theory. Englewood Cliffs, NJ: Prentice-Hall.

Barnett, P. A., \& Gotlib, I. H. (1988). Psychosocial functioning and depression: Distinguishing among antecedents, concomitants, and consequences. Psychological Bulletin, 104, 97-126.

Baron, R. M., \& Kenny, D. A. (1986). The moderator-mediator variable distinction in social psychological research: Conceptual, strategic, and statistical considerations. Journal of Personality and Social Psychology, 51, 1173-1182.

Bates, J. E., Maslin, C. A., \& Frankel, K. A. (1985). Attachment security, mother-child interaction, and temperament as predictors of behavior- 
problem ratings at age 3 years. In I. Bretherton \& E. Waters (Eds.), Growing points of attachment theory and research. Monographs of the Society for Research in Child Development, 50(1-2, Serial No. 209), 167-193.

Baumrind, D. (1971). Current patterns of parental authority. Developmental Psychology Monograph, 4(1, Pt. 2).

Baumrind, D. (1993). The average expectable environment is not good enough: A response to Scarr. Child Development, 64, 1299-1317.

Beardslee, W. R., Schultz, L. H., \& Selman, R. L. (1987). Level of social-cognitive development, adaptive functioning, and DSM-III diagnoses in adolescent offspring of parents with affective disorders: Implications for the development of the capacity for mutuality. Developmental Psychology, 23, 807-815.

BeII, R. Q., \& Harper, L. V. (1977). Child effects on adults. Hillsdale, NJ: Erlbaum.

Belle, D. (1982). Lives in stress. Beverly Hills, CA: Sage.

Belsher, G., \& Costello, C. G. (1988). Relapse after recovery from unipolar depression: A critical review. Psychological Bulletin, 104, 84-96.

Belsky, J. (1984). The determinants of parenting: A process model. Child Development, 55, 83-96.

Bergeman, C. S., Plomin, R., Pedersen, N. L., McClearn, G. E., \& Nesselroade, J. R. (1990). Genetic and environmental influences on social support: The Swedish Adoption/Twin Study of Aging (SATSA). Journal of Gerontology, 45, 101-106.

Bettes, B. A. (1988). Maternal depression and motherese: Temporal and intonational features. Child Development, 59, 1089-1096.

Biglan, A., Hops, H., Sherman, L., Friedman, L. S., Arthur, J., \& Osteen, V. (1985). Problem-solving interactions of depressed women and their husbands. Behavior Therapy, 16, 431-451.

Billings, A., \& Moos, R. (1982). Psychosocial theory and research on depression: An integrative framework and review. Clinical Psychology Review, 2, 213 237.

Billings, A. G., \& Moos, R. (1983). Comparison of children of depressed and nondepressed parents: A social environmental perspective. Journal of Abnormal Child Psychology, 11, 483-486.

Billings, A. G., \& Moos, R. H. (1985). Children of parents with unipolar depression: A controlled 1-year follow-up. Journal of Abnormal Child Psychology, 14, 149-166.

Blehar, M. C., \& Oren, D. A. (1995). Women's increased vulnerability to mood disorders: Integrating psychobiology and epidemiology. Depression, 3, 3-12

Boyle, M. H. P., \& Pickles, A. R. (1997). Influence of Maternal Depressive Symptoms on Ratings of Childhood Behavior. Journal of Abnormal Child Psychology, 25, 399-412.

Braungart, J. M. (1994). Genetic influence on "environmental" measures. In J. C. DeFries, R. Plomin, \& D. W. Fulker (Eds.), Nature and nurture during middle childhood (pp. 233-248). Cambridge, MA: Blackwell.

Breznitz, Z., \& Friedman, S. L. (1988). Toddlers' concentration: Does maternal depression make a difference? Journal of Child Psychology and Psychiatry, 29, 267-279.

Breznitz, Z., \& Sherman, T. (1987). Speech patterning of natural discourse of well and depressed mothers and their young children. Child Development, 58, 395-400.

Bronfenbrenner, U. (1986). Ecology of the family as a context for human development: Research perspectives. Developmental Psychology, 22, 723-742.

Bronfenbrenner, U., \& Ceci, S. J. (1994). Nature-nurture reconceptualized in developmental perspective: A bioecological model. Psychological Review, 101, 568-586.

Brown, G. W., \& Harris, T. (1978). Social origins of depression. New York: Free Press.

Bruce, M. L., \& Kim, K. M. (1992). Differences in the effects of divorce on major depression in men and women. American Journal of Psychiatry, 149, 914-917.
Bugental, D. B., Blue, J., Cortez, V., Fleck, K., \& Rodriguez, A. (1992). Influences of witnessed affect on information processing in children. Child Development, 63, 774-786.

Burke, K. C., Burke, J. D., Regier, D. A., \& Rae, D. S. (1990). Age at onset of selected mental disorders in five community populations. Archives of General Psychiatry, 47, 511-518.

Calkins, S. D. (1994). Origins and outcomes of individual differences in emotion regulation. In N. A. Fox (Ed.), The development of emotion regulation: Biological and behavioral considerations. Monographs of the Society for Research in Child Development, 59(240), 53-72.

Calkins, S. D., Fox, N. A., \& Marshall, T. R. (1996). Behavioral and physiological correlates of inhibition in infancy. Child Development, 67 , 523-540.

Campbell, S. B., \& Cohn, J. F. (1997). The timing and chronicity of postpartum depression: Implications for infant development. In P. Murray (Ed.), Postpartum depression and child development (pp. 165-197). New York: Guilford Press.

Campbell, S. B., Cohn, J. F., \& Meyers, T. (1995). Depression in first-time mothers: Mother-infant interaction and depression chronicity. Developmental Psychology, 31, 349-357.

Campos, J. J., \& Steinberg, C. R. (1981). Perception, appraisal and emotion: The onset of social referencing. In M. E. Lamb \& L. R. Sherrod (Eds.), Infant social cognition: Empirical and theoretical considerations (pp. 273-314). Hillsdale, NJ: Erlbaum.

Caplan, G. (1989). Prevention of psychopathology and maladjustment in children of divorce. In M. Brambring, F. Losel, \& H. Skowronek (Eds.), Children at risk: Assessment, longitudinal research, and intervention. Prevention and intervention in childhood and adolescence (Vol. 7, pp. 367-394). Berlin, Germany: Walter de Gruyter.

Carro, M. G., Grant, K. E., Gotlib, I. H., \& Compas, B. E. (1993). Postpartum depression and child development: An investigation of mothers and fathers as sources of risk and resilience. Milestones in the development of resilience. Development and Psychopathology, 5, 567579.

Chabrol, H., Bron, N., \& Le Camus, J. (1996). Mother-infant and fatherinfant interactions in postpartum depression. Infant Behavior and Development, 19, 149-152.

Chambers, C. D., Johnson, K. A., Dick, L. M., Felix, R. J., \& Jones, K. L. (1996). Birth outcomes in pregnant women taking fluoxetine. New England Journal of Medicine, 335, 1010-1015.

Cherny, S. S., Fulker, D. W., Corley, R. P., Plomin, R., \& DeFries, J. C. (1994). Continuity and change in infant shyness from 14 to 20 months. Behavior Genetics, 24, 365-379.

Cicchetti, D., \& Schneider-Rosen, K. (1986). An organizational approach to childhood depression. In M. Rutter, C. E. Izard, \& P. B. Read (Eds.), Depression in young people: Developmental and clinical perspectives (pp. 71-134). New York: Guilford Press.

Clarke, A. S., \& Schneider, M. L. (1993). Prenatal stress has long-term effects on behavioral responses to stress in juvenile rhesus monkeys. Developmental Psychobiology, 26, 296-304.

Clarke, A. S., Wittwer, D. J., Abbott, D. H., \& Schneider, M. L. (1994). Long-term effects of prenatal stress on HPA axis activity in juvenile rhesus monkeys. Developmental Psychobiology, 27, 256-269.

Cloninger, C. R., Sigvardsson, S., Bohman, M., \& von Knorring, A. (1983). Predisposition to petty criminality in Swedish adoptees: II. Cross-fostering analysis of gene-environment interaction. Archives of General Psychiatry, 39, 1242-1247.

Cogill, S. R., Caplan, H. L., Alexandra, H., Robson, K. M., \& Kumar, R. (1986). Impact of maternal depression on cognitive development of young children. British Medical Journal, 292, 1165-1167.

Cohen, S., \& Wills, T. A. (1985). Stress, social support, and the buffering hypothesis. Psychological Bulletin, 98, 310-357.

Cohn, J., \& Campbell, S. (1992). Influence of maternal depression on infant affect regulation. In D. Cicchetti \& S. Toth (Eds.), Developmental 
Perspectives on Depression (Vol. 4, pp. 103-130). Rochester, NY: University of Rochester.

Cohn, J. F., Campbell, S. B., Matias, R., \& Hopkins, J. (1990). Face-to-face interactions of postpartum depressed and nondepressed mother-infant pairs at 2 months. Developmental Psychology, 26, 15-23.

Cohn, J. F., Matias, R., Tronick, E. Z., Connell, D., \& Lyons-Ruth, D. (1986). Face-to-face interactions of depressed mothers and their infants. In E. Z. Tronick \& T. Field (Eds.), Maternal depression and infant disturbance (pp. 31-46). San Francisco: Jossey-Bass.

Compas, B. E. (1987). Coping with stress during childhood and adolescence. Psychological Bulletin, 101, 393-403.

Conrad, M., \& Hammen, C. (1989). Role of maternal depression in perceptions of child maladjustment. Journal of Consulting and Clinical Psychology, 57, 663-667.

Coplan, J. D., Andrews, M. W., Rosenblum, L. A., Owens, M. J., Friedman, S., Gorman, J. M., \& Nemeroff, C. B. (1996). Persistent elevations of cerebrospinal fluid concentrations of corticotropin-releasing factor in adult nonhuman primates exposed to early-life stressors: Implications for the pathophysiology of mood and anxiety disorders. Proceedings of the National Academy of Science USA, 93, 1619-1623.

Copper, R. L., Goldenberg, R. L., Das, A., Elder, N., Swain, M., Norman, G., Ramsey, R., Cotroneo, P., Collins, B. A., Johnson, F., Jones, P., \& Meier, A. M. (1996). The preterm prediction study: Maternal stress is associated with spontaneous preterm birth at less than thirty-five weeks' gestation. American Joumal of Obstetrics and Gynecology, 175, 12861292.

Costello, E. J., \& Angold, A. (1988). Scales to assess child and adolescent depression: Checklists, screens and nets. Journal of the American Academy of Child and Adolescent Psychiatry, 27, 726-737.

Cox, A. D., Puckering, C., Pound, A., \& Mills, M. (1987). The impact of maternal depression in young children. Joumal of Child Psychology and Psychiatry, 28, 917-928.

Coyne, J. C., \& Gotlib, I. H. (1983). The role of cognition in depression: A critical appraisal. Psychological Bulletin, 94, 472-505.

Crowe, R. R. (1975). An adoption study of antisocial personality. Archives of General Psychiatry, 31, 785-791.

Crowther, J. H. (1985). The relationship between depression and marital maladjustment: A descriptive study. Journal of Nervous and Mental Disease, 173, 227-231.

Cummings, E. M., \& Davies, P. T. (1994). Maternal depression and child development. Journal of Child Psychology and Psychiatry, 35, 73-112.

Cutrona, D. E., \& Troutman, B. R. (1986). Social support, infant temperament, and parenting self-efficacy: A mediational model of postpartum depression. Child Development, 57, 1507-1518.

Davidson, R. J., \& Fox, N. A. (1988). Cerebral asymmetry and emotion: Development and individual differences. In D. L. Molfese \& S. J. Segalowitz (Eds.), Brain lateralization in children: Developmental implications. New York: Guilford Press.

Davies, P. T., \& Windle, M. (1997). Gender-specific pathways between maternal depressive symptoms, family discord, and adolescent adjustment. Developmental Psychology, 33, 657-668.

Dawson, G. (1994). Frontal electroencephalographic correlates of individual differences in emotion expression in infants: A brain systems perspective on emotion. In N. A. Fox (Ed.), The development of emotion regulation: Biological and behavioral considerations. Monographs of the Society for Research in Child Development, 59(2-3), 135-151.

Dawson, G., Frey, K., Panagiotides, H., Osterling, J., \& Hessl, D. (1997). Infants of depressed mothers exhibit atypical frontal brain activity: A replication and extension of previous findings. Journal of Child Psychology and Psychiatry and Allied Disciplines, 38, 179-186.

Dawson, G., Grofer Klinger, L., Panagiotides, H., Hill, D., \& Spieker, S. (1992). Frontal lobe activity and affective behavior of infants of mothers with depressive symptoms. Child Development, 63, 725-737.

Dawson, G., Hessl, D., \& Frey, K. (1994). Social influences on early developing biological and behavioral systems related to risk for affective disorder. Development and Psychopathology, 6, 759-779.

Deiter-Deckard, K., \& Dodge, K. A. (1997). Externalizing behavior problems and discipline revisited: Nonlinear effects and variation by culture, context, and gender. Psychological Inquiry, 8, 161-175.

Depue, R. A., \& Monroe, S. M. (1986). Conceptualization and measurement of human disorder in life stress research: The problem of chronic disturbance. Psychological Bulletin, 99, 36-51.

Digdon, N., \& Gotlib, I. H. (1985). Developmental considerations in the study of childhood depression. Developmental Review, 5, 162-199.

Dodge, K. A. (1990). Developmental psychopathology in children of depressed mothers. Developmental Psychology, 26, 3-6.

Downey, G., \& Coyne, J. C. (1990). Children of depressed parents: An integrative review. Psychological Bulletin, 108, 50-76.

Downey, G., \& Walker, E. (1989). Social cognition and adjustment in children at risk for psychopathology. Developmental Psychology, 25, $835-845$.

Dumas, J. E., Gibson, J. A., \& Albin, J. B. (1989). Behavioral correlates of maternal depressive symptomatology in conduct-disorder children. Journal of Consulting and Clinical Psychology, 57, 516-521.

Dunn, J., \& Kendrick, C. (1981). Siblings and their mothers: Developing relationships within the family. In M. Lamb \& B. Sutton-Smith (Eds.), Sibling relationships: Their development and significance (pp. 39-59). Hillsdale, NJ: Erlbaum.

Egeland, B., \& Farber, E. (1984). Infant-mother attachment: Factors related to its development and changes over time. Child Development, 55, 753-771.

Eiden, R. D., \& Leonard, K. E. (1996). Paternal alcohol use and the mother-infant relationship. Development and Psychopathology, 8(2), 307-323.

Emery, R., Weintraub, S., \& Neale, J. M. (1982). Effects of marital discord on the children of schizophrenic, affectively disordered, and normal parents. Journal of Abnormal Child Psychology, 10, 215-228.

Emory, E., Hatch, M., Blackmore, C., \& Strock, B. (1993). Psychophysiologic responses to stress during pregnancy. Unpublished manuscript, Emory University, Atlanta, GA.

Emory, E., Walker, E., \& Cruz, A. (1983). Fetal heart rate: II. Behavioral correlates. Psychophysiology, 19, 680-686.

Emory, E. K., Schlackman, L. J., \& Fiano, K. (1996). Drug-hormone interactions on neurobehavioral responses in human neonates. Infant Behavior and Development, 19, 213-220.

Fendrich, M., Warner, V., \& Weissman, M. M. (1990). Family risk factors, parental depression, and psychopathology in offspring. Developmental Psychology, 26, 40-50.

Fergusson, D. M., Horwood, L. J., \& Lynskey, M. T. (1995). Maternal depressive symptoms and depressive symptoms in adolescents. Journal of Child Psychology and Psychiatry and Allied Disciplines, 36, 11611178.

Field, T. (1984). Early interactions between infants and their postpartum depressed mothers. Infant Behavior and Development, 7, 517-522.

Field, T. (1992). Infants of depressed mothers. Development and Psychopathology, 4, 9-66.

Field, T. (1994). The effects of mother's physical and emotional unavailability on emotion regulation. In N. A. Fox (Ed.), The development of emotion regulation: Biological and behavioral considerations. Monographs of the Society for Research in Child Development, 59(2-3, Serial No. 240), 208-227.

Field, T., Fox, N., Pickens, J., Nawrocki, T., \& Soutullo, D. (1995). Right frontal EEG activation in 3- to 6-month-old infants of "depressed" mothers. Developmental Psychology, 31, 358-363.

Field, T., Healy, B., Goldstein, S., \& Guthertz, M. (1990). Behavior state matching and synchrony in mother-infant interactions of nondepressed versus depressed dyads. Developmental Psychology, 26, 7-14.

Field, T., Healy, B., \& LeBlanc, W. (1989). Sharing and synchrony of 
behavior states and heart rate in nondepressed versus "depressed" mother-infant interactions. Infant Behavior and Development, 12, 357376.

Field, T., Pickens, J., Fox, N. A., Nawrocki, T., \& Gonzalez, J. (1995) Vagal tone in infants of depressed mothers. Development and Psychopathology, 7, 227-231.

Field, T., Sandberg, D., Garcia, R., Vega-Lahr, N., Goldstein, S., \& Guy, L. (1985). Prenatal problems, postpartum depression, and early motherinfant interactions. Developmental Psychology, 12, 1152 1156.

Field, T. M. (1998, April). Depressed mothers and their newborns. Paper presented at the 11 th Biennial Conference on Infant Studies, Atlanta, GA.

Fleming, A., Ruble, D., Flett, G., \& Shaul, D. (1988). Postpartum adjustment in first-time mothers: Relations between mood, maternal attitudes, and mother-infant interactions. Developmental Psychology, 24, 71-8I.

Forehand, R., Lautenschlager, G. J., Faust, J., \& Graziano, W. G. (1986). Parent perceptions and parent-child interactions in clinic-referred children: A preliminary investigation of the effects of maternal depressive moods. Behavior Research and Therapy, 24, 73-75.

Fox, N. A. (1994). Dynamic cerebral processes underlying emotion regulation. In N. A. Fox (Ed.), The development of emotion regulation: Biological and behavioral considerations. Monographs of the Society for Research in Child Development, 59(2-3, Serial No. 240), 152-166.

Friedlander, S., Weiss, D. S., \& Taylor, J. (1986). Assessing the influence of maternal depression on the validity of the Child Behavior Checklist. Journal of Abnormal Child Psychology, 14, 123-133.

Garber, J., \& Robinson, N. S. (1997). Cognitive vulnerability in children at risk for depression. Cognition and Emotion, 11, 619-635.

Garmezy, N. (1985). Stress-resistant children: The search for protective factors. In J. E. Stevenson (Ed.), Recent research in developmental psychopathology (pp. 213-233). Journal of Child Psychology and Psychiatry(Book Suppl. 4).

Gelfand, D., \& Teti, D. (1990). The effects of maternal depression on children. Clinical Psychology Review, 10, 329-353.

Ghodsian, M., Zajicek, E., \& Wolkind, S. (1984). A longitudinal study of maternal depression and child behaviour problems. Journal of Child Psychology and Psychiatry and Allied Disciplines, 25, 91-109.

Gianino, A., \& Tronick, E. (1985). The mutual regulation model: The infant's self and interactive regulation and coping and defensive capacities. In T. Field, P. McCabe, \& N. Schneiderman (Eds.), Stress and coping (pp. 47-68). Hillsdale, NJ: Erlbaum.

Glover, V. (1997). Maternal stress or anxiety in pregnancy and emotional development of the child. British Journal of Psychiatry, 171, 105-106.

Glover, V., Teixeira, J., Gitau, R., \& Fisk, N. (1998, April). Links berween antenatal maternal anxiety and the fetus. Paper presented at the 11th Biennial Conference on Infant Studies, Atlanta, GA.

Goldsmith, D. F., \& Rogoff, B. (1995). Sensitivity and teaching by dysphoric and nondysphoric women in structured versus unstructured situations. Parental depression and distress: Implications for development in infancy, childhood, and adolescence. Developmental Psychology, 3I, 388-394.

Goldsmith, D. F., \& Rogoff, B. (1997). Mothers' and toddlers' coordinated joint focus of attention: Variations with maternal dysphoric symptoms. Developmental Psychology, 33, 113-119.

Goldsmith, H. H., Buss, K. A., \& Lemery, K. S. (1997). Toddler and childhood temperament: Expanded content, stronger genetic evidence, new evidence for the importance of environment. Developmental Psychology, 33, 891-905.

Goodman, S. H. (1984). Children of disturbed parents: The interface between research and intervention. The American Journal of Community Psychology, 12, 663-687.

Goodman, S. H. (1992). Understanding the effects of depressed mothers on their children. In E. F. Waiker, R. H. Dworkin, \& B. A. Cornblatt (Eds.),
Progress in Experimental Personality and Psychopathology Research (pp. 47-109). New York: Springer

Goodman, S. H., Adamson, L. B., Riniti, J., \& Cole, S. (1994). Mothers expressed attitudes: Associations with maternal depression and children's self-esteem and psychopathology. Journal of the American Academy of Child and Adolescent Psychiatry, 33, 1265-1274.

Goodman, S. H., Brogan, D., Lynch, M. E., \& Fielding, B. (1993). Social and emotional competence in children of depressed mothers. Child Development, 64, 516-531.

Goodman, S. H., Lahey, B. B., Fielding, B., Dulcan, M., Narrow, W., \& Regier, D. (1997). Representativeness of clinical samples of youth with mental disorders: A preliminary population-based study. Journal of Abnormal Psychology, 107, 3-14.

Goodman, S. H., Sewell, D. R., Cooley, E. L., \& Leavitt, N. (1993). Assessing levels of adaptive functioning: The Role Functioning Scale. Community Mental Health Journal, 29, 119-131.

Gotlib, I. H. (1982). Self-reinforcement and depression in interpersonal interaction: The role of performance level. Journal of Abnormal Psychology, 91, 3-13.

Gotlib, I. H., \& Avison, W. R. (1993). Children at risk for psychopathology. In C. G. Costello (Ed.), Basic issues in psychopathology (pp. 271-319). New York: Guilford Press.

Gotlib, I. H., \& Beach, S. R. H. (1995). A marital/family discord model of depression: Implications for therapeutic intervention. In N. S. Jacobson \& A. S. Gurman (Eds.), Clinical handbook of couple therapy (pp. 411-436). New York: Guilford Press.

Gotlib, 1. H., Gilboa, E., \& Sommerfeld, B. K. (in press). Cognitive functioning in depression: Nature and origins. In R. J. Davidson (Ed.), Wisconsin Symposium on Emotion (Vol. 1). New York: Oxford University Press.

Gotlib, I. H., \& Goodman, S. H. (1999). Children of parents with depression. In W. K. Silverman \& T. H. Ollendick (Eds.), Developmental issues in the clinical treatment of children and adolescents (pp. 415432). New York: Allyn \& Bacon.

Gotlib, I. H., \& Hammen, C. L. (1992). Psychological aspects of depression: Toward a cognitive-interpersonal integration. Chichester, England: Wiley.

Gotlib, I. H., \& Hooley, J. M. (1988). Depression and marital distress: Current status and future directions. In S. Duck (Ed.), Handbook of Personal Relationships (pp. 543-570). Chichester, England: Wiley.

Gotlib, I. H., \& Krasnoperova, E. (1998). Biased information processing as a vulnerability factor for depression. Behavior Therapy, 29, 603-617.

Gotlib, I. H., \& Lee, C. M. (1990). Children of depressed mothers: A review and directions for future research. In C. D. McCann \& N. S. Endler (Eds.), Depression: New directions in theory, research, and practice (pp. 187-208). Toronto, Canada: Wall \& Thompson.

Gotlib, 1. H., \& Lee, C. M. (1996). Impact of parental depression on young children and infants. In C. Mundt, M. J. Goldstein, K. Hahlweg, \& P. Fiedler (Eds.), Interpersonal factors in the origin and course of affective disorders (pp. 218-239). London: Royal College of Psychiatrists

Gotlib. I. H., Lewinsohn, P. M., \& Seeley, J. R. (1998). Consequences of depression during adolescence: Marital status and marital functioning in early adulthood. Journal of Abnormal Psychology, 107, 686-690.

Gotlib, I. H., \& MacLeod, C. (1997). Information processing in anxiety and depression: A cognitive developmental perspective. In J. Burack \& J. Enns (Eds.), Attention, development, and psychopathology (pp. 350378). New York: Guilford Press.

Gotlib, I. H., \& Meltzer, S. J. (1987). Depression and the perception of social skill in dyadic interaction. Cognitive Therapy and Research, 11, $41-53$.

Gotlib, I. H., \& Neubauer, D. L. (in press). Information-processing approaches to the study of cognitive biases in depression. In S. Johnson, A. Hayes, T. Field, P. McCabe, \& N. Schneiderman (Eds.), Stress, coping, and depression. Hillsdale, NJ: Erlbaum. 
Gotlib, I. H., Ranganath, C., \& Rosenfeld, J. P. (1998). Frontal EEG alpha asymmetry, depression, and cognitive functioning. Cognition and Emotion, 12, 449-478.

Gotlib, I. H., \& Robinson, L. A. (1982). Responses to depressed individuals: Discrepancies between self-report and observer-rated behavior. Journal of Abnormal Psychology, 91, 231-240.

Gotlib, I. H., \& Wheaton, B. (Eds.). (1997). Stress and adversity over the life course: Trajectories and turning points. New York: Cambridge University Press.

Gotlib, I. H., \& Whiffen, V. E. (1989). Depression and marital functioning: An examination of specificity and gender differences. Journal of $A B$ normal Psychology, 98, 23-30.

Gotlib, I. H., \& Whiffen, V. E. (1991). The interpersonal context of depression: Implications for theory and research. In W. H. Jones \& D. Perlman (Eds.), Advances in personal relationships (Vol. 3, pp. 177 206). London: Jessica Kingsley.

Gotlib, I. H., Whiffen, V. E., Wallace, P., \& Mount, J. H. (1991). A prospective investigation of postpartum depression: Factors involved in onset and recovery. Journal of Abnormal Psychology, 100, 122-132.

Gottman, J. M., Katz, L. F., \& Hooven, C. (1996). Parental meta-emotion philosophy and the emotional life of families: Theoretical models and preliminary data. Joumal of Family Psychology, 10, 243-268.

Gross, D., Conrad, B., Fogg, L., Willis, L., \& Garvey, C. (1995). A longitudinal study of maternal depression and preschool children's mental health. Nursing Research, 44(2), 96-101.

Grych, J. H., \& Fincham, F. D. (1990). Marital conflict and children's adjustment: A cognitive-contextual framework. Psychological Bulletin, $108,267-290$.

Gurtman, M. B. (1986). Depression and the response of others: Reevaluating the reevaluation. Journal of Abnormal Psychology, 95, 99-101.

Hammen, C. (1988). Self cognitions, stressful events, and the prediction of depression in children of depressed mothers. Journal of Abnormal Child Psychology, 16, 347-360.

Hammen, C. (1990). Vulnerability to depression: Personal, situational, and family aspects. In R. Ingram (Ed.), Contemporary approaches to depression: Treatment, research, and theory (pp. 59-69). New York: Plenum.

Hammen, C. (1991). Depression runs in families: The social context of risk and resilience in children of depressed mothers. New York: SpringerVerlag.

Hammen, C. (1992). Life events and depression: The plot thickens. American Joumal of Community Psychology, 20, 179-193.

Hammen, C., Adrian, C., \& Hiroto, D. (1988). A longitudinal test of the attributional vulnerability model in children at risk for depression. British Journal of Clinical Psychology, 27, 37-46.

Hammen, C., Burge, D., \& Adrian, C. (1991). Timing of mother and child depression in a longitudinal study of children at risk. Journal of Consulting and Clinical Psychology, 59, 341-345.

Hammen, C., Burge, D., \& Stansbury, K. (1990). Relationship of mother and child variables to child outcomes in a high risk sample: A causal modeling analysis. Developmental Psychology, 26, 24-30.

Hammen, C., Gordon, D., Burge, D., Adrian, C., Jaenicke, C., \& Hiroto, D. (1987). Maternal affective disorders, illness, and stress: Risk for children's psychopathology. American Journal of Psychiatry, 144, 736741.

Handley, S. L., Dunn, T. L., Waldron, G., \& Baker, J. M. (1980). Tryptophan, cortisol and puerperal mood. British Journal of Psychiatry, 136, 498-508.

Harnish, J. D., Dodge, K. A., Valente, E., \& Conduct Problems Prevention Research Group. (1995). Mother-child interaction quality as a partial mediator of the roles of maternal depressive symptomatology and socioeconomic status in the development of child behavior problems. Child Development, 66, 739-753.

Harrington, R., Rutter, M., \& Fombonne, E. (1996). Developmental path- ways in depression: Multiple meanings, antecedents, and endpoints. Development and Psychopathology, 8, 601-616.

Harter, S. (1983). Developmental perspectives on the self-system. In P. H. Mussen (Ed.), Handbook of Child Psychology (Vol. 4, pp. 275-385). New York: Wiley.

Hautzinger, M., Linden, M., \& Hoffman, N. (1982). Distressed couples with and without a depressed partner: An analysis of their verbal interaction. Journal of Behavior Therapy and Experimental Psychiatry, 13, 307-314.

Hay, D. F. (1997). Postpartum depression and cognitive development. In P. Murray (Ed.), Postpartum depression and child development (pp. 85110). New York: Guilford Press.

Hayward, R. C., Gotlib, I. H., Schraedley, P., \& Litt, I. (1998). Pubertal status and the emergence of gender differences in depression. Unpublished manuscript, Stanford University.

Hedegaard, M., Henriksen, T. B., Secher N. J., Hatch, M. C., \& Sabroe, S. (1996). Do stressful life events affect duration of gestation and risk of preterm delivery? Epidemiology, 7, 339-345.

Heim, C., Owens, M. J., Plotsky, P. M., \& Nemeroff, C. B. (1997). Persistent changes in corticotropin-releasing factor systems due to early life stress: Relationship to the pathophysiology of major depression and post-traumatic stress disorder. Psychopharmacology Bulletin, 33, 185-192.

Hinchliffe, M., Hooper, D., \& Roberts, F. J. (1978). The melancholy marriage. New York: Wiley.

Hirsch, B. J., Moos, R. H., \& Reischl, T. M. (1985). Psychosocial adjustment of adolescent children of a depressed, arthritic, or normal parent. Journal of Abnormal Psychology, 94, 154-164.

Hoffman, L. W. (1985). The changing genetics/socialization balance. Journal of Social Issues, 41, 127-148.

Hoffman, L. W. (1994). Commentary on Plomin, R. (1994): A proof and a disproof questioned. Social Development, 3, 60-63.

Holmbeck, G. N. (1997). Toward terminological, conceptual, and statistical clarity in the study of mediators and moderators: Examples from the child-clinical and pediatric psychology literatures. Joumal of Consulting and Clinical Psychology, 65, 599-610.

Hops, H. (1996). Intergenerational transmission of depressive symptoms: Gender and developmental considerations. In C. Mundt, M. J. Goldstein, $\mathrm{K}$. Hahlweg, \& P. Fiedler (Eds.), Interpersonal factors in the origin and course of affective disorders (pp. 113-129). London: Royal College of Psychiatrists.

Hops, H., Biglan, A., Sherman, L., Arthur, J., Friedman, L., \& Osteen, V. (1987). Home observations of family interactions of depressed women Journal of Consulting and Clinical Psychology, 55, 341-346.

Hops, H., Sherman, L., \& Biglan, A. (1990). Maternal depression, marital discord, and children's behavior: A developmental perspective. In G. R. Patterson (Ed.), Depression and aggression in family interactions (pp. 185-208). Hillsdale, NJ: Erlbaum.

Hossain, Z., Field, T., Gonzalez, J., Malphurs, J., Valle, C., \& Pickens, J. (1994). Infants of depressed mothers interact better with their nondepressed fathers. Infant Mental Health Journal, 15, 348-357.

Ingram, R. E. (1990). Self-focused attention in clinical disorders: Review and a conceptual model. Psychological Bulletin, 107, 156-176.

Institute of Medicine. (1985). Preventing low birthweight. Washington, DC: National Academy Press.

Jacobson, R. H., \& Anderson, E. (1982). Interpersonal skills deficits and depression in college students: A sequential analysis of the timing of self-disclosures. Behavior Therapy, 13, 271-282.

Jaenicke, C., Hammen, C., Zupan, B., Hiroto, D., Gordon, D., Adrian, C., \& Burge, D. (1987). Cognitive vulnerability in children at risk for depression. Journal of Abnormal Child Psychology, 15, 559-572.

Joiner, T. E., \& Wagner, K. D. (1995). Attributional style and depression in children and adolescents: A meta-analytic review. Clinical Psychology Review, 15, 777-798. 
Kagan, J. (1994). On the nature of emotion. In N. Fox (Ed.), The development of emotion regulation: Biological and behavioral considerations. Monographs of the Society for Research in Child Development, 59(2-3), 7-24.

Kagan, J., Reznick, J. S., \& Snidman, N. (1988, April). Biological bases of childhood shyness. Science, 240, 167-171.

Katz, L. F., \& Gottman, J. M. (1993). Patterns of marital conflict predict children's internalizing and externalizing behaviors. Developmental Psychology, 29, 940-950.

Kay, G., Tarcic, N., Poltyrev, T., \& Weinstock, M. (1998). Prenatal stress depresses immune function in rats. Physiology and Behavior, 63, 397-402.

Keller, M. B., Beardslee, W. R., Dorer, D. J., Lavori, P. W., Samuelson, H., \& Klerman, G. R. (1986). Impact of severity and chronicity of parental affective illness on adaptive functioning and psychopathology in children. Archives of General Psychiatry, 43, 930-937.

Keller, M. B., Lavori, P. W., Mueller, T. I., Endicott, J., Coryell, W., Hirschfeld, R. M. A., \& Shea, T. (1992). Time to recovery, chronicity, and levels of psychopathology in major depression: A 5-year prospective follow-up of 431 subjects. Archives of General Psychiatry, 49, $809-816$

Keller, M. B., \& Shapiro, R. W. (1981). Major depressive disorder: Initial results from a one-year prospective naturalistic follow-up study. Journal of Nervous and Mental Disorders, 169, 761-768.

Keiler, M. B., Shapiro, R. W., Lavori, P. W., \& Wolfe, N. (1982). Recovery in major depressive disorder: Analysis with the life table and regression models. Archives of General Psychiatry, 51, 8-19.

Kendler, K. S., Kessler, R. C., Walters, E. E., MacLean, C. J., Sham, P. C., Neale, M. C., Heath, A. C., \& Eaves, L. J. (1995). Stressful life events, genetic liability and onset of an episode of major depression in women. American Journal of Psychiatry, 152, 833-842.

Kendler, K. S., Neale, M. C., Heath, A. C., Kessler, R. C., \& Eaves, L. J. (1991). Life events and depressive symptoms: A twin study perspective. In P. McGuffin \& R. M. Murray (Eds.), The new genetics of mental illness (pp. 146-164). Stoneham, MA: Butterworth-Heinemann.

Kendler, K. S., Neale, M. C., Kessier, R. C., Heath, A. C., \& Eaves, L. J. (1993). A twin study of recent life events and difficulties. Archives of General Psychiatry, 50, 789-796.

Kessler, R. C., Kendler, K. S., Heath, A., Neale, M. C., \& Eaves, L. J. (1992). Social support, depressed mood, and adjustment to stress: A genetic epidemiologic investigation. Journal of Personality and Social Psychology, 62, 257-272.

Klimes-Dougan, B., \& Bolger, A. K. (1998). Coping with maternal depressed affect and depression: Adolescent children of depressed and well mothers. Journal of Youth and Adolescence, 27, 1-15.

Kochanska, G. (1987, April). Socialization of young children's anger by well and depressed mothers. Paper presented at the Society for Research in Child Development, Baltimore.

Kochanska, G., Kuczynski, L., \& Maguire, M. (1989, April). Patterns of mutual influence between well and depressed mothers and their 5-yearold children. Paper presented at the Society for Research in Child Development, Kansas City, MO.

Kochanska, G., Kuczynski, L., Radke-Yarrow, M., \& Welsh, J. D. (1987). Resolutions of control episodes between well and affectively ill mothers and their young children. Journal of Abnormal Child Psychology, 15, $441-456$.

Kochanska, G., Radke-Yarrow, M., Kuczynski, L., \& Friedman, S. (1987). Normal and affectively ill mothers' beliefs about their children. American Journal of Orthopsychiatry, 57, 345-350.

Kovacs, M. (1992). Children's Depression Inventory (CDI) Manual. North Tonawanda, NY: Multi-Health Systems.

Kovacs, M., Devlin, B., Pollock, M., Richards, C., \& Mukerji, P. (1997). A controlled family history study of childhood-onset depressive disorder. Archives of General Psychiatry, 54, 613-623.
Kowalik, D. L., \& Gotlib, I. H. (1987). Depression and marital interaction: Concordance between intent and perception of communication. Journal of Abnormal Psychology, 96, 127-134.

Kutcher, S., \& Marton, P. (1991). Affective disorders in first-degree relatives of adolescent onset bipolars, unipolars, and normal controls. Journal of the American Academy of Child and Adolescent Psychiatry, 30, 75-78.

Ladd, C. O., Owens, M. J., \& Nemeroff, C. B. (1996). Persistent changes in corticotropin-releasing factor neuronal systems induced by maternal deprivation. Endocrinology, 137, 1212-1218.

Lahey, B. B., Hartdagen, S. E., Frick, P. J., McBurnett, K., Connor, R., \& Hynd, G. W. (1988). Conduct disorder: Parsing the confounded relation to parental divorce and antisocial personality. Journal of Abnormal Psychology, 97, 334-337.

Lee, C. M., \& Gotlib, I. H. (1989). Clinical status and emotional adjustment of children of depressed mothers. American Journal of Psychiatry, $146,478-483$.

Lee, C. M., \& Gotlib, I. H. (1991a). Adjustment of children of depressed mothers: A ten-month follow-up. Journal of Abnormal Psychology, 100 , 473-477.

Lee, C. M., \& Gotlib, I. H. (1991b). Family disruption, parental availability, and child adjustment: An integrative review. In R. J. Prinz (Ed.), Advances in the behavioral assessment of children and families (Vol. 5, pp. 166-199). London: Jessica Kingsley.

Lewinsohn, P. M., Hoberman, H. M., \& Rosenbaum, M. (1988). A prospective study of risk factors for unipolar depression. Journal of Abnormal Psychology, 97, 251-264.

Livingood, A. B., Daen, P., \& Smith, B. D. (1983). The depressed mother as a source of stimulation for her infant. Journal of Clinical Psychol. ogy, 39, 369-375.

Loehlin, J. C. (1992). Genes and environment in personality development. Beverly Hills, CA: Sage.

Loehlin, J. C., \& Nichols, R. C. (1976). Heredity, environment, and personality. Austin: University of Texas Press.

Lykken, D., \& Tellegen, A. (1996). Happiness is a stochastic phenomenon. Psychological Science, 7, 186-189.

Lytton, H. (1990). Child and parent effects in boys' conduct disorder: A reinterpretation. Developmental Psychology, 26, 683-697.

Maccoby, E. E., \& Martin, J. A. (1983). Socialization in the context of the family: Parent-child interaction. In E. M. Hetherington (Ed.), Handbook of Child Psychology: Socialization, Personality, and Social Development (Vol. 4, pp. 1-102). New York: Wiley.

McBurnett, K., Lahey, B. B., Frick, P. J., Risch, C., Loeber, R., Hart, E. L., Christ, M. A., \& Hanson, K. S. (1991). Anxiety, inhibition, and conduct disorder in children: II. Relation to salivary cortisol. Journal of the American Academy of Child and Adolescent Psychiatry, 30, 192-196.

McGauhey, P. J., Starfield, B., Alexander, C., \& Ensminger, M. E. (1991). Social environment and vulnerability of low birth weight children: A social-epidemiological perspective. Pediatrics, 88, 943-953.

McGue, M., \& Lykken, D. T. (1992). Genetic influence on risk of divorce. Psychological Science, 3, 368-373.

McGuffin, P., \& Katz, R. (1993). Genes, adversity, and depression. In R. Plomin \& G. E. McClearn (Eds.), Nature and nurture and psychology (pp. 217-230). Washington, DC: American Psychological Association.

McGuffin, P., Katz, R., Rutherford, J., Watkins, S., Farmer, A. E., \& Gottesman, I. I. (1993). Twin studies as vital indicators of phenotypes in molecular genetic research. In T. J. Bouchard \& P. Propping (Eds.), Twins as a tool of behavioral genetics (pp. 243-256). New York: Wiley.

Mednick, S. A., \& Schulsinger, F. (1968). Some premorbid characteristics related to breakdown in children with schizophrenic mothers. In D. Rosenthal \& S. S. Kety (Eds.), The transmission of schizophrenia (pp. 267-291). Oxford, England: Pergamon Press.

Merikangas, K. R. (1984). Divorce and assortative mating among depressed patients. American Journal of Psychiatry, 141, 74-76. 
Merikangas, K. R., Prusoff, B. A., \& Weissman, M. M. (1988). Parental concordance for affective disorders: Psychopathology in offspring. Journal of Affective Disorders, 15, 279-290.

Merikangas, K. R., Weissman, M. M., Prusoff, B. A., \& John, K. (1988). Assortative mating and affective disorders: Psychopathology in offspring. Psychiatry, 51, 48-57.

Milberger, S., Biederman, J., Faraone, S. V., Chen, L., \& Jones, J. (1996). Is maternal smoking during pregnancy a risk factor for attention deficit hyperactivity disorder in children? American Journal of Psychiatry, 153 , $1138-1142$.

Mitchell, J., McCauley, E., Burke, P., Calderon, R., \& Schloredt, K. (1989). Psychopathology in parents of depressed children and adolescents. Journal of the American Academy of Child and Adolescent Psychiatry, 28, 352-357.

Monroe, S. M., \& Simons, A. D. (1991). Diathesis-stress theories in the context of life-stress research: Implications for depressive disorders. Psychological Bulletin, 110, 406-425.

Mueller, T. I., Keller, M. B., Leon, A. C., Solomon, D. A., Shea, M. T., Coryell, W., \& Endicott, J. (1996). Recovery after 5 years of unremitting major depressive disorder. Archives of General Psychiatry, 53, 794-799.

Murray, K. T., \& Sines, J. O. (1996). Parsing the genetic and nongenetic variance in children's depressive behavior. Journal of Affective Disorders, 36(4), 23-34.

Murray, L. (1992). The impact of postnatal depression on infant development. Journal of Child Psychology and Psychiatry and Allied Disciplines, 33, 543-561.

Murray, L., \& Cooper, P. J. (1997). Postpartum depression and child development. New York: Guilford Press.

Murray, L., Fiori-Cowley, A., Hooper, R., \& Cooper, P. (1996). The impact of postnatal depression and associated adversity on early motherinfant interactions and later infant outcomes. Child Development, 67, 2512-2526.

Nulman, I., Rovet, J., Stewart, D. E., Wolpin, J., Gardner, H. A., Theis, J. G., Kulin, N., \& Koren, G. (1997). Neurodevelopment of children exposed in utero to antidepressant drugs. New England Journal of Medicine, 336, 258-262.

Nurnberger, J., Goldin, L. R., \& Gershon, E. S. (1986). Genetics of psychiatric disorders. In G. Winokur \& P. Clayton (Eds.), The medical basis of psychiatry (pp. 486-521). Philadelphia: Saunders.

O'Connor, T., Hetherington, E. M., Reiss, D., \& Plomin, R. (1995). A twin-sibling study of observed parent-adolescent interactions. Child Development, 66, 812-829.

O'Hara, M. W. (1986). Social support, life events, and depression during pregnancy and the puerperium. Archives of General Psychiatry, 43, $569-573$.

Paarlberg, K. M., Vingerhoets, A. J., Passchier, J., Dekker, G. A., \& Van Geijn, H. P. (1995). Psychosocial factors and pregnancy outcome: A review with emphasis on methodological issues. Journal of Psychosomatic Research, 39, 563-595.

Pastuszak, A., Schick-Boschetto, B., Zuber, C., Feldkamp, M., Pinelli, M., Sihn, S., Donnenfeld, A., McCormack, M., Leen-Mitchell, M., Woodland, C., Gardner, A., Ham, M., \& Koren, G. (1993). Pregnancy outcome following first-trimester exposure to fluoxetine (Prozac). Journal of the American Medical Association, 269, 2246-2248.

Patterson, G. R. (1982). Coercive family process. Eugene, OR: Castalia.

Petersen, A. C. (1988). Adolescent development. Annual Review of Psychology, 39, 583-607.

Pianta, R., Erickson, M. F., Wagner, N., Kreutzer, T., \& Egeland, B. (1990). Early predictors of referral for special services: Child-based measures versus mother-child interaction. School Psychology Review, 19, 240-250.

Plomin, R. (1990, April 13). The role of inheritance in behavior. Science, $248,183-188$.
Plomin, R. (1994). Genetics and experience: The interplay between nature and nurture. Thousand Oaks, CA: Sage.

Plomin, R., \& Daniels, D. (1987). Why are children in the same family so different from one another? Behavioral and Brain Sciences, 10, 1-16.

Plomin, R., Emde, R. N., Braungart, J. M., Campos, J., Corley, R., Fulker, D. W., Kagan, J., Reznick, J. S., Robinson, J., Zahn-Waxler, C., \& DeFries, J. C. (1993). Genetic change and continuity from fourteen to twenty months: The MacArthur Longitudinal Twin Study. Child Development, 64, 1354-1376.

Plomin, R., Reiss, D., Hetherington, E. M., \& Howe, G. (1994). Nature and nurture: Genetic contributions to measures of the family environment. Developmental Psychology, 30, 32-43.

Poltyrev, T., Keshet, G. I., Kay, G., \& Weinstock, M. (1996). Role of experimental conditions in determining differences in exploratory behavior of prenatally stressed rats. Developmental Psychobiology, 29, 453-462.

Porges, S. W. (1992). Vagal tone: A physiological marker of stress vulnerability. Pediatrics, 90, 498-504.

Porges, S. W., Doussard-Roosevelt, J. A., \& Maiti, A. K. (1994). Vagal tone and the physiological regulation of emotion. In N. A. Fox (Ed.), The development of emotion regulation: Behavioral and biological considerations. Monographs of the Society for Research in Child Development, 59(2-3), 167-186, 250-283.

Portales, A. L., Doussard-Roosevelt, J. A., Lee, H. B., \& Porges, S. W. (1992). Infant vagal tone predicts 3-year child behavior problems. Infant Behavior and Development, 15, 636.

Pound, A., Cox, A., Puckering, C., \& Mills, M. (1985). The impact of maternal depression on young children. In J. E. Stevenson (Ed.), Recent research in developmental psychopathology (pp. 3-10). Oxford, England: Pergamon Press.

Puig-Antich J. (1984). Clinical and treatment aspects of depression in childhood and adolescence. Pediatric Annals, 13, 37-41, 44-45.

Puig-Antich, J., Goetz, D., Davies, M., Kaplan, T., Davies, S., Ostrow, L., Asnis, L., Toomey, J., Iyengar, S., \& Ryan, N. (1989). A controlled family history study of prepubertal major depressive disorder. Archives of General Psychiatry, 46, 406-418.

Puig-Antich, J., Goetz, R., Hanlon, C., Tabrizi, M. A., Davies M., \& Weitzman, E. (1983). Sleep architecture and REM sleep measures in prepubertal major depressives: Studies during recovery from a major depressive episode in a drug free state. Archives of General Psychiatry, 40, 187-192.

Pyszczynski, T., \& Greenberg, J. (1987). Self-regulatory perseveration and the depressive self-focusing style: A self-awareness theory of reactive depression. Psychological Bulletin, 102, 122-138.

Radke-Yarrow, M., Belmont, B., Nottelmann, E., \& Bottomly, L. (1990). Young children's self-conceptions: Origins in the natural discourse of depressed and normal mothers and their children. In D. Cicchetti \& M. Beeghly (Eds.), The self in transition: Infancy to childhood (pp. 345361). Chicago: University of Chicago Press.

Radke-Yarrow, M., Cummings, E. M., Kuczynski, L., \& Chapman, M. (1985). Patterns of attachment in two- and three-year olds in normal families and families with parental depression. Child Development, 56, 884-893.

Radke-Yarrow, M., \& Nottelmann, E. (1989, April). Affective development in children of well and depressed mothers. Paper presented at Society for Research in Child Development, Kansas City, MO.

Radke-Yarrow, M., \& Sherman, T. (1990). Hard growing: Children who survive. In J. Rolf, A. S. Masten, D. Cicchetti, K. H. Nuechterlein, \& S. Weintraub (Eds.), Risk and protective factors in the development of psychopathology (pp. 97-119). Cambridge, England: Cambridge University Press.

Radke-Yarrow, M., \& Sherman, T. L. (1985, August). Social-emotional development: Qualities of parenting by normal and depressed mothers. 
Paper presented at the 93rd Annual Convention of the American Psychological Association, Los Angeles, CA.

Radke-Yarrow, M., Zahn-Waxler, C., Richardson, D. T., Susman, A., \& Martinez, P. (1994). Caring behavior in children of clinically depressed and well mothers. Child Development, 65, 1405-1414.

Rende, R. D., Plomin, R., Reiss, D., \& Hetherington, E. M. (1993). Genetic and environmental influences on depressive symptomatology in adolescence: Individual differences and extreme scores. Journal of Child Psychology and Psychiatry, 34, 1387-1398.

Richters, J. E. (1992). Depressed mothers as informants about their children: A critical review of the evidence for distortion. Psychological Bulletin, 112, 485-499.

Richters, J. E., \& Pellegrini, D. S. (1989). Depressed mothers' judgments about their children: An examination of the depression-distortion hypothesis. Child Development, 60, 1068-1075.

Rickard, K. M., Forehand, R., Wells, K. C., Griest, D. L., \& McMahon, R. J. (1981). Factors in the referral of children for behavioural treatment: A comparison of mothers of clinic-referred deviant, clinic-referred nondeviant, and non-clinic children. Behaviour Research and Therapy, 19, 201-205.

Roberts, J. E., \& Gotlib, I. H. (1997). Social support and personality in depression: Implications from behavioral genetics. In G. R. Pierce, B. Lakey, I. G. Sarason, \& B. R. Sarason (Eds.), Social support and personality: Structure, process, and change (pp. 187-214). New York: Plenum.

Rothbart, M. K., Ziaie, H., \& O'Boyle, C. G. (1992). Self-regulation and emotion in infancy: Emotion and its regulation in early development. In N. Eisenberg \& R. A. Fabes (Eds.), New directions for child development (Vol. 55, pp. 7-23). San Francisco: Jossey-Bass.

Rubin, K. H., Hymel, S., Mills, R. S., \& Rose-Krasnor, L. (1991). Conceptualizing different developmental pathways to and from social isolation in childhood. In D. Cicchetti \& S. L. Toth (Eds.), Rochester Symposium on Developmental Psychopathology: Vol. 2, Internalizing and externalizing expressions of dysfunction (pp. 91-122). Hillsdale, NJ: Erlbaum.

Ruscher, S. M., \& Gotlib, I. H. (1988). Marital interaction patterns of couples with and without a depressed partner. Behavior Therapy, 19, 455-470.

Rutter, M., \& Quinton, P. (1984). Parental psychiatric disorder: Effects on children. Psychological Medicine, 14, 853-880.

Rutter, M., Silberg, J., \& Simonoff, E. (1993). Whither behavioral genetics? A developmental psychopathological perspective. In R. Plomin \& G. McClearn (Eds.), Nature, nurture and psychology (pp. 433-456). Washington, DC: American Psychological Association.

Ryan, N. D., \& Dahl, R. E. (1993). The biology of depression in children and adolescents. In J. J. Mann \& D. J. Kupfer (Eds.), Biology of depressive disorders, Part B: Subtypes of depression and comorbid disorders (pp. 37-58). New York: Plenum.

Sameroff, A. J. (1990, March). Prevention of developmental psychopathology using the transactional model: Perspectives on host, risk agent, and environmental interactions. Paper presented at the Conference of The Present Status and Future Needs of Research on Prevention of Mental Disorders, Washington, DC.

Sameroff, A. J., Barocas, R., \& Seifer, R. (1984). The early development of children born to mentally ill women. In N. F. Watt, E. J. Anthony, L. C. Wynne, \& J. Rolf (Eds.), Children at risk for schizophrenia (pp. 482-514). New York: Cambridge University Press.

Sameroff, A. J., Seifer, R., Zax, M., \& Barocas, R. (1987). Early indicators of developmental risk: Rochester longitudinal study. Schizophrenia Bulletin, 13, 383-394.

Schaughency, E. A., \& Lahey, B. B. (1985). Mothers' and fathers' perceptions of child deviance: Roles of child behavior, parental depression, and marital satisfaction. Journal of Consulting and Clinical Psychology, 53, 718-723.
Schneider, M. L. (1992). Prenatal stress exposure alters postnatal behavioral expressions under conditions of novelty challenge in rhesus monkey infants. Developmental Psychobiology, 25, 529-540.

Schwartz, C. E., Snidman, N., \& Kagan, J. (1996). Early childhood temperament as a determinant of externalizing behavior in adolescence. Development and Psychopathology, 8, 527-537.

Seligman, M. E. P., \& Peterson, C. (1986). A learned helplessness perspective on childhood depression: Theory and research. In M. Rutter, C. E. Izard, \& P. B. Read (Eds.), Depression in young people: Developmental and clinical perspectives (pp. 223-249). New York: Guilford Press.

Sharp, D., Hay, D. F., Pawlby, S., Schmucker, G., Allen, H., \& Kumar, R. (1995). The impact of postnatal depression on boys' intellectual development. Journal of Child Psychology and Psychiatry and Allied Disciplines, 36, 1315-1336.

Singer, J. M., \& Fagen, J. W. (1992). Negative affect, emotional expression, and forgetting in young infants. Developmental Psychology, 28, 43-57.

Smith, R., Cubis, J., Brinsmead, M., Lewin, T., Singh, B., Owens, P., Eng-Cheng, C., Hall, C., Adler, R., Lovelock, M., Hurt, D., Rowley, M., \& Nolan, M. (1990). Mood changes, obstetric experience and alterations in plasma cortisol, beta-endorphin and corticotrophin releasing hormone during pregnancy and the puerperium. Journal of Psychosomatic Research, 34, 53-69.

Snyder, J. (1991). Discipline as a mediator of the impact of maternal stress and mood on child conduct problems. Development and psychopathology, 3, 263-276.

Sroufe, L. A., \& Rutter, M. (1984). The domain of developmental psychopathology. Child Development, 55, 17-29.

Stansbury, K., \& Gunnar, M. R. (1994). Adrenocortical activity and emotion regulation. In N. A. Fox (Ed.), The development of emotion regulation: Biological and behavioral considerations. Monographs of the Society for Research in Child Development, 59(2-3), 108-134.

Stein, A., Gath, D., Bucker, J., Bond, A., Day, A., \& Cooper, P. (1991). The relationship between postnatal depression and mother-child interaction. British Journal of Psychiatry, 158, 46-52.

Tellegen, A., Lykken, D. T., Bouchard, T. J., Wilcox, K. J., Segal, N. L., \& Rich, S. (1988). Personality similarity in twins reared apart and together. Journal of Personality and Social Psychology, 54, 1031-1039.

Teti, D. M., Gelfand, D. M., Messinger, D. S., \& Isabella, R. (1995). Maternal depression and the quality of early attachment: An examination of infants, preschoolers, and their mothers. Developmental Psychology, 31, 364-376.

Teti, D. M., Gelfand, D. M., \& Pompa, J. (1990). Depressed mothers' behavioral competence with their infants: Demographic and psychosocial correlates. Development and Psychopathology, 2, 259-270.

Thapar, A., \& McGuffin, P. (1996). The genetic etiology of childhood depressive symptoms: A developmental perspective. Development and Psychopathology, 8, 751-760.

Thomas, A. M., \& Forehand, R. (1991). The relationship between paternal depressive mood and early adolescent functioning. Journal of Family Psychology, 4, 260-271.

Thomas, A. M., Forehand, R., \& Neighbors, B. (1995). Changes in maternal depressive mood: Unique contributions to adolescent functioning over time. Adolescence, 30, 43-52.

Thompson, R. A. (1994). Emotion regulation: A theme in search of definition. In N. A. Fox (Ed.), The development of emotion regulation: Biological and behavioral considerations. Monographs of the Society for Research in Child Development, 59(2-3), 25-52.

Todd, R. D., Geller, B., Neuman, R., Fox, L. W., \& Hickok, J. (1996). Increased prevalence of alcoholism in relatives of depressed and bipolar children. Journal of the American Academy of Child and Adolescent Psychiatry, 35, 716-724.

Todd, R. D., Neuman, R., Geller, B., Fox, L. W., \& Hickok, J. (1993). 
Genetic studies of affective disorders: Should we be starting with childhood onset probands? Journal of the American Academy of Child and Adolescent Psychiatry, 32, 1164-1171.

Tronick, E. Z. (1989). Emotions and emotional communication in infants. American Psychologist, 44, 112-119.

Tronick, E. Z., \& Gianino, A. F. (1986). The transmission of maternal disturbance to the infant. In E. Z. Tronick \& T. Field (Eds.), Maternal depression and infant disturbance (pp. 5-12). San Francisco: Jossey-Bass.

Tsuang, M. T., \& Faraone, S. V. (1990). The genetics of mood disorders. Baltimore: Johns Hopkins University Press.

Turkewitz, G., \& Devenny, D. A. (1993). Timing and the shape of development. In G. Turkewitz \& D. A. Devenny (Eds.), Developmental time and timing (pp. 1-11). Hillsdale, NJ: Erlbaum.

Vygotsky, L. S. (1987). Thinking and speech. In R. W. Rieber \& A. S. Carton (Eds.), The collected works of L. S. Vygotsky (pp. 39-285; N. Minick, Trans.). New York: Plenum.

Walden, T. A., \& Ogan, T. A. (1988). The development of social referencing. Child Development, 59, 1230-1240.

Walker, E., Neumann, C. C., Baum, K., Davis, D. M., DiForio, D., \& Bergman, A. (1996). The developmental pathways to schizophrenia: Potential moderated effects of stress. Development and Psychopathology, 8, 647-666.

Webster-Stratton, C., \& Hammond, M. (1988). Maternal depression and its relationship to life stress, perceptions of child behavior problems, parenting behaviors, and child conduct problems. Journal of Abnormal Child Psychology, 16, 299-315.

Weissman, M. M. (1988). Psychopathology in the children of depressed parents: Direct interview studies. In D. L. Dunner, E. S. Gershon, \& J. B. Barrett (Eds.), Relatives at risk for mental disorder (pp. 143-159). New York: Raven.

Weissman, M. M., Gammon, G. D., John, K., Merikangas, K. R., Warner, V., Prusoff, B., \& Sholomskas, D. (1987). Children of depressed parents: Increased psychopathology and early onset of major depression. Archives of General Psychiatry, 44, 847-853.

Weissman, M. M., Prusoff, B. A., Gammon, G. D., Merikangas, K. R., Leckman, J. F., \& Kidd, K. K. (1984). Psychopathology in the children (ages 6-18) of depressed and normal parents. Journal of the American Academy of Child Psychiatry, 23, 78-84.

Weissman, M. M., Warner, V., Wickramaratne, P., \& Prusoff, B. A. (1988). Early-onset major depression in parents and their children. Journal of Affective Disorders, 15, 269-277.

Werner, E. E., \& Smith, R. S. (1980). An epidemiologic perspective on some antecedents and consequences of childhood mental health problems and learning disabilities. Annual Progress in Child Psychiatry and Child Development, 133-147.

Whiffen, V. E., \& Gotlib, I. H. (1989). Infants of postpartum depressed mothers: Temperament and cognitive status. Journal of Abnormal Psychology, 98, 274-279.

Williams, M. T., Hennessy, M. B., \& Davis, H. N. (1998). Stress during pregnancy alters rat offspring morphology and ultrasonic vocalizations. Physiology and Behavior, 63, 337-343.

Williamson, D. E., Ryan, N. D., Birmaher, B., Dahl, R. E., Kaufman, J., Rao, U., \& Puig-Antich, J. (1995). A case-control family history study of depression in adolescents. Journal of the American Academy of Child and Adolescent Psychiatry, 34, 1596-1607.

Zahn-Waxler, C. (1996). Environment, biology, and culture: Implications for adolescent development. Developmental Psychology, 32, 571-573.

Zahn-Waxler, C., Cummings, E. M., Iannotti, R. J., \& Radke-Yarrow, M. (1984). Young children of depressed parents: A population at risk for affective problems. In D. Cicchetti \& K. Schneider-Rosen (Eds.), Childhood depression: New directions for child development (pp. 81-105). San Francisco: Jossey-Bass.

Zekoski, E. M., O'Hara, M. W., \& Wills, K. E. (1987). The effects of maternal mood on mother-infant interaction. Journal of Abnormal Child Psychology, 15, 361-378.

Zuckerman, B. S., Bauchner, H., Parker, S., \& Cabral, H. (1990). Maternal depressive symptoms during pregnancy and newborn irritability. Developmental and Behavioral Pediatrics, 11, 190-194.

Received February 18, 1997

Revision received June 12, 1998 Accepted September 6, 1998

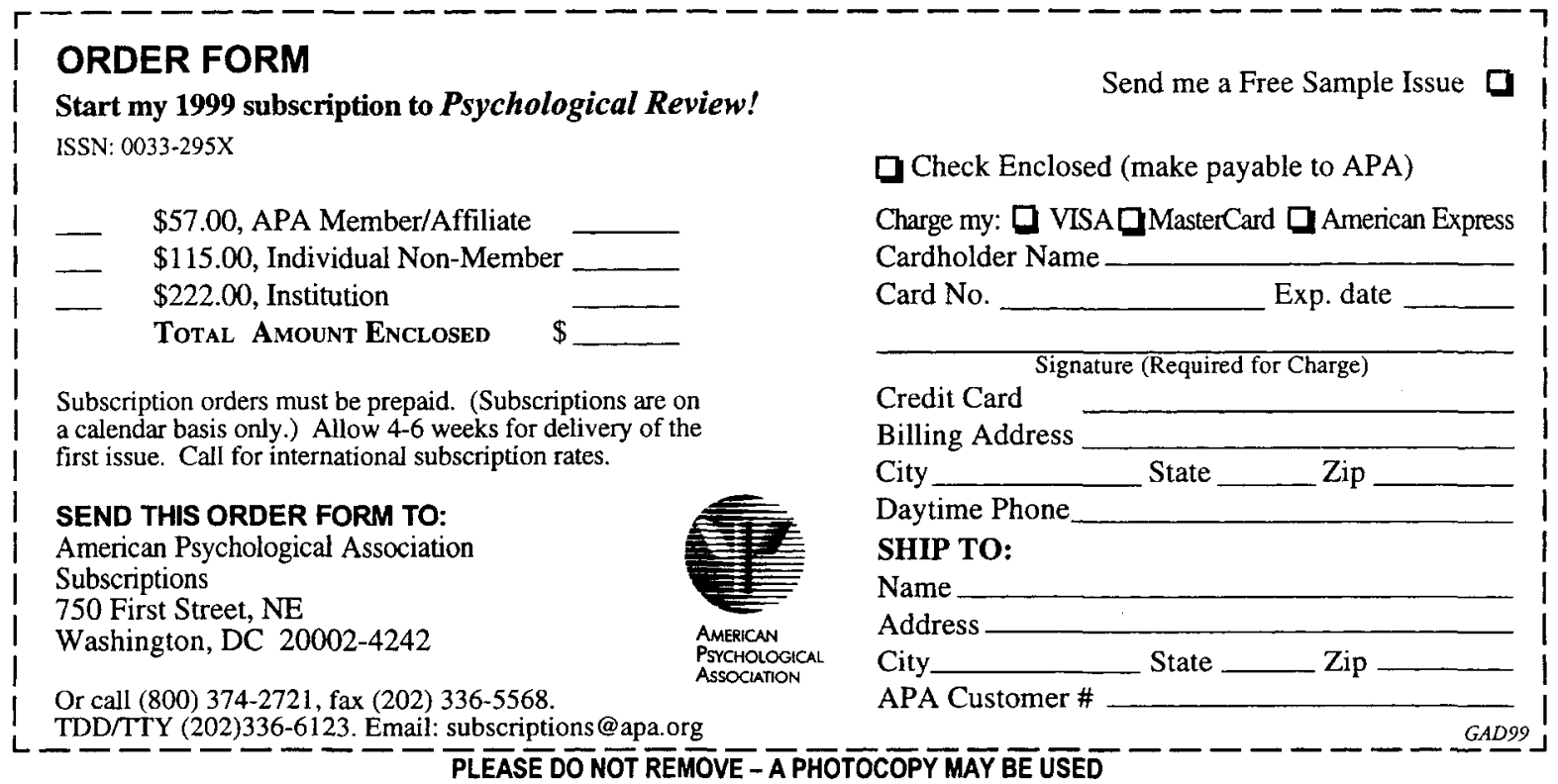

